Check for updates

Cite this: RSC Adv., 2019, 9, 35509

Received 10th September 2019 Accepted 18th October 2019

DOI: $10.1039 / c 9 r a 07283 g$

rsc.li/rsc-advances

\section{Micro-manganese as a weight agent for improving the suspension capability of drilling fluid and the study of its mechanism}

\begin{abstract}
Jingyuan Ma, ${ }^{\text {ab }}$ Peizhi Yu, ${ }^{\text {ab }}$ Boru Xia ${ }^{\text {ab }}$ and Yuxiu An (D) *ab
The contradiction between the sag stability of weighted materials and the rheological properties of drilling fluids is one of the main technical difficulties in high-density drilling fluids. Thus, understanding the suspension mechanism of weighting materials is the key to improving the sag stability of weighting materials. In this study, micro-manganese $\left(\mathrm{Mn}_{3} \mathrm{O}_{4}\right)$ was compared with the commonly used weighting agent barite to study the suspension mechanism of $\mathrm{Mn}_{3} \mathrm{O}_{4}$. The weighting effect of $\mathrm{Mn}_{3} \mathrm{O}_{4}$ and barite was evaluated by static and dynamic sag tests, rheological property measurements and filtration property tests. The evaluation experiment results showed that the sag stability of $\mathrm{Mn}_{3} \mathrm{O}_{4}$ was better than that of barite, and $\mathrm{Mn}_{3} \mathrm{O}_{4}$ could significantly increase the suspension capacity of drilling fluids and improve their rheology property. The scanning electron microscopy (SEM) and other test results indicate that the small and uniform spherical structure of micro-manganese not only causes it to have less friction, but also intense Brownian motion in drilling fluid, which weakens the sag caused by gravity. The large specific surface area of $\mathrm{Mn}_{3} \mathrm{O}_{4}$ results in the strong adsorption of water molecules and polymers in drilling fluids, resulting in the formation of a hydrated film on the surface of the $\mathrm{Mn}_{3} \mathrm{O}_{4}$ particles and physical crosslinking with polymer chains. This prevents sagging caused by the adsorption of small particles to form large particles. The key findings of this work are expected to provide a basis for improving the sag stability of weighting materials in drilling fluids and better the application of micro-manganese in drilling fluids.
\end{abstract}

\section{Introduction}

Pressure control of the formation is critical in drilling operations. The pressure is typically controlled using high density minerals such as barite and hematite to increase the density of drilling fluids. However, the control of rheology and sag stability is one of the main technical difficulties in high-density drilling fluids. Sag refers to the sinking of the weighting material caused by factors such as gravity, resulting in significant changes in the density of the drilling fluid and deterioration of the performance of the drilling fluid. ${ }^{1,2}$ Both static sag that occurs when the drilling fluid is stopping circulating and dynamic sag, which happens in the circulation, can result in wellbore instability, stuck pipe and other problems. ${ }^{3-5}$ There are many factors affecting sag such as the design parameters of the well, and the performance of drilling fluids and weighting materials. Among them, the performance of drilling fluids is closely related to the selection of weighting materials. ${ }^{6,7}$

${ }^{a}$ School of Engineering and Technology, China University of Geosciences (Beijing), Haidian District, Beijing 100083, China.E-mail: anyx@cugb.edu.cn

${ }^{b}$ Key Laboratory of Deep Geo Drilling Technology, Ministry of Land and Resources, Beijing 100083, China
Barite is the most commonly used weighting material to adjust the density of drilling fluid. However, the problems of filter cake thickening, increasing equivalent circulation density (ECD), excessive torque and friction caused by barite sagging often occur. ${ }^{8-10}$ In addition, the problems such as the poor rock carrying capability and the increase in friction caused by the sagging of barite are distinctive in all horizontal wells. Thus, if sagging is not effectively solved, it can cause great difficulties to the drilling process and increase the drilling cost. Accordingly, optimizing other weighting materials to replace barite is one of the effective ways to solve the problem of barite sagging. According to Stokes' formula (1) and the static shear force formula (2) for drilling fluid suspension weighting materials:

$$
\begin{gathered}
v=d^{2}\left(\rho_{\mathrm{s}}-\rho_{\mathrm{f}}\right) g /(18 \eta) \\
\pi d^{2} \tau=(1 / 6) \pi d^{3}\left(\rho_{\mathrm{s}}-\rho_{\mathrm{f}}\right) g
\end{gathered}
$$

where $v$ is the sag rate of the weighting material particles $(\mathrm{cm}$ $\mathrm{s}^{-1}$ ), $d$ is the diameter of the weighting agent particles $(\mathrm{cm}), \eta$ is the viscosity of the system (mPa s), $\rho_{\mathrm{s}}$ and $\rho_{\mathrm{f}}$ are the density of weighting material particles and drilling fluid $\left(\mathrm{g} \mathrm{cm}^{-3}\right)$, respectively, $\tau$ is the static shear force of the drilling fluid $(\mathrm{Pa})$, and $g$ is the acceleration of gravity $\left(\mathrm{m} \mathrm{s}^{-2}\right)$. The smaller the 
particle size of the weighting material, the smaller the sag velocity and static shear force required, and then, the better the suspension and sag stability of drilling fluids. ${ }^{6}$ Naderi's study of the sag trends of barite, hematite, ilmenite and micromanganese further confirms this view. ${ }^{\mathbf{1 1}}$ Weighting materials with different particle size, distribution and morphology have a great influence on the rheological stability and other properties of drilling fluids. ${ }^{12}$ The micro-powder weighting materials that are frequently studied and used include micronized barite, ${ }^{\mathbf{1 3 , 1 4}}$ micron-scale hematite/ilmenite ${ }^{\mathbf{1 5 - 1 8}}$ and micromanganese. ${ }^{\mathbf{1 9 , 2 0}}$ Micro-manganese $\left(\mathrm{Mn}_{3} \mathrm{O}_{4}\right)$ has been extensively studied in recent years due to its unique shape and superior suspension stability.

Micro-manganese $\left(\mathrm{Mn}_{3} \mathrm{O}_{4}\right)$ as a weighting material refers to ultrafine particles $\left(\mathrm{Mn}_{3} \mathrm{O}_{4}\right)$ having an average particle diameter of less than $1 \mu \mathrm{m}$ synthesized by blowing air through a molten metal during a process following the production of manganese metal. ${ }^{11}$ A unique advantage of micro-manganese particles is their extremely low size and high density $\left(4.8 \mathrm{~g} \mathrm{~cm}^{-3}\right)$. Also, their sag rate is much lower than that of barite, and thus they have excellent sag stability. ${ }^{21}$ In fact, there have been some studies on the feasibility of using $\mathrm{Mn}_{3} \mathrm{O}_{4}$ instead of barite as a weighting material. For example, some studies have shown that $\mathrm{Mn}_{3} \mathrm{O}_{4}$-weighted drilling fluids are less likely to cause corrosion to the drill bit and damage to the formations than barite-weighted drilling fluids. ${ }^{22-24}$ Furthermore, the acid solubility of $\mathrm{Mn}_{3} \mathrm{O}_{4}$ makes the filter cake formed by $\mathrm{Mn}_{3} \mathrm{O}_{4}$ easier to be removed than that formed by barite during the reservoir development process. ${ }^{25}$ However, there are still some problems in the use of micro-manganese, such as particle agglomeration, large fluid loss, and high cost. ${ }^{26-29}$ Researchers have conducted extensive research on the dispersibility of micro-manganese $\mathrm{e}^{28,30-32}$ and the removal of its filter cake. ${ }^{33-36}$ However, existing research has focused on the use of micro-manganese in drilling fluids, and there is no detailed discussion on the suspension stability mechanism of $\mathrm{Mn}_{3} \mathrm{O}_{4}$. As is known, the biggest problem in high density drilling fluids is the sag of barite. The key to solving this problem is to replace the weighting material or increase the suspension capacity of barite. Thus, understanding the suspension mechanism of $\mathrm{Mn}_{3} \mathrm{O}_{4}$ can not only result in the better use of $\mathrm{Mn}_{3} \mathrm{O}_{4}$ in drilling fluid, but also provide a basis for improving the suspension capacity of barite.

This work aims to study the suspension capacity of barite and micro-manganese $\left(\mathrm{Mn}_{3} \mathrm{O}_{4}\right)$ in different density drilling fluids (1.8-2.8 $\mathrm{g} \mathrm{cm}^{-3}$ ), and to explore the suspension mechanism of $\mathrm{Mn}_{3} \mathrm{O}_{4}$. According to the tests of sag performance and rheological properties, the $\mathrm{Mn}_{3} \mathrm{O}_{4}$-weighted drilling fluids showed significantly better suspension capacity and rheological properties than that of the barite-weighted drilling fluids at different densities. The suspension mechanism of $\mathrm{Mn}_{3} \mathrm{O}_{4}$ was proposed by studying the microstructure and surface properties of $\mathrm{Mn}_{3} \mathrm{O}_{4}$ and barite. As shown in Fig. 1, particles are subjected to gravity, buoyancy and drag force in solution. When gravity plays a major role, the particles will sag to the bottom of the container. Barite was more susceptible to sag due to its large particle size and sharp shape. On the contrary, $\mathrm{Mn}_{3} \mathrm{O}_{4}$ had a uniform spherical shape and a particle diameter of less than 1 $\mu \mathrm{m}$, which resulted in intense Brownian motion of the particles. The strong adsorbability by the large specific surface area allowed the micro-manganese particles to interact with each molecule in the solution, and thus exhibited superior suspension property than that of barite.

\section{Experimental}

\subsection{Materials}

Brown-red micro-manganese $\left(\mathrm{Mn}_{3} \mathrm{O}_{4}\right)$ with density of $4.8 \mathrm{~g} \mathrm{~cm}^{-3}$ was provided by Great Technology Co., Ltd. Barite, which is mainly composed of $\mathrm{BaSO}_{4}$, with a density of $4.2 \mathrm{~g} \mathrm{~cm}^{-3}$ met the
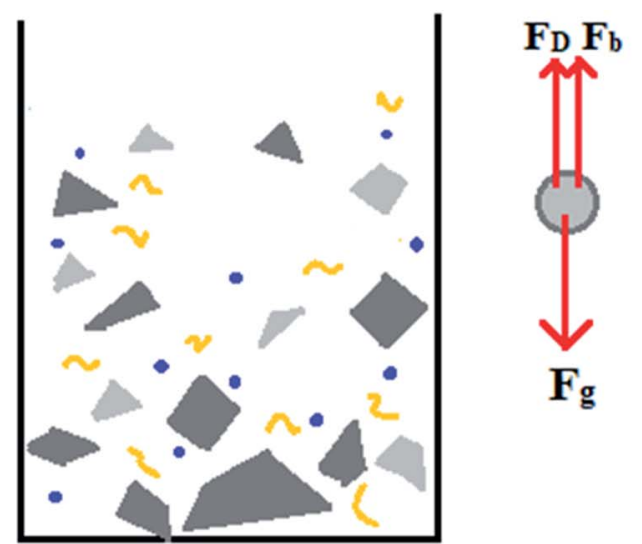

Clay particles

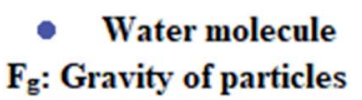

Barite particles

Polymer chains

Fb: Buoyancy of particles

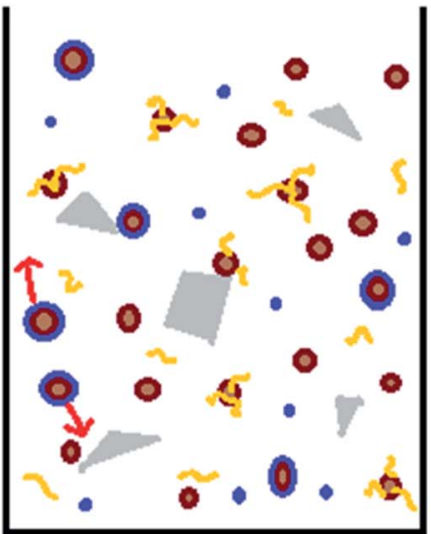

Micro-manganese $\left(\mathrm{Mn3} \mathrm{O}_{4}\right)$ particles

\section{FD: Drag force of particles}

Fig. 1 Sag schematic diagram of barite and $\mathrm{Mn}_{3} \mathrm{O}_{4}$. 
API standards. The standard bentonite was obtained from England (IMERYS) and other drilling fluid treatment agents such as DS-301, ammonium salt, potassium humate (KHm), sodium carbonate $\left(\mathrm{Na}_{2} \mathrm{CO}_{3}\right)$, sodium hydroxide $(\mathrm{NaOH})$, potassium polyacrylamide (K-PAM), polymer fluid loss additive (RHPT-2), inhibitor (DS-302), sulfonated brown coal (SMC), brown coal resin (SPNH), emulsified paraffin (RHJ-1) and lubricant (JM-1) used in this study were all supplied by a domestic oil addictive company.

\subsection{Fluid preparation}

The base slurry was prepared by mixing $15 \mathrm{~g}$ of bentonite and $2.5 \mathrm{~g}$ of anhydrous sodium carbonate with $1000 \mathrm{~cm}^{3}$ of distilled water. The suspension was stirred quickly for $20 \mathrm{~min}$, and then stirred at a low speed and aged for $24 \mathrm{~h}$ at room temperature. Then, 0.2 wt $\%$ of DS-301 as a coating agent, 0.5 wt $\%$ of ammonium salt as an inhibitor and $3 \mathrm{wt} \%$ of potassium humate as a fluid loss agent were slowly poured into a certain amount of the base slurry while stirring to prepare water-based drilling fluids (WDFs). Finally, the WDF was weighted to a fixed density $\left(1.8 \mathrm{~g} \mathrm{~cm}^{-3}, 2.0 \mathrm{~g} \mathrm{~cm}^{-3}, 2.2 \mathrm{~g} \mathrm{~cm}^{-3}, 2.4 \mathrm{~g} \mathrm{~cm}^{-3}, 2.6 \mathrm{~g} \mathrm{~cm}^{-3}\right.$, and $\left.2.8 \mathrm{~g} \mathrm{~cm}^{-3}\right)$ using barite and micro-manganese $\left(\mathrm{Mn}_{3} \mathrm{O}_{4}\right)$ as weighting materials, and formulated into barite/WDFs and $\mathrm{Mn}_{3} \mathrm{O}_{4} / \mathrm{WDFs}$, respectively.

\subsection{Sag stability property evaluation}

2.3.1 Static sag test. The WDF with a certain density was allowed to stand at room temperature for $10 \mathrm{~min}$, and an equal amount $(10 \mathrm{~mL})$ of the top layer and bottom fluid was taken to calculate the difference in density. The static sag coefficient (SF) can be calculated according to the formula: $\mathrm{SF}=\rho_{\mathrm{b}} /\left(\rho_{\mathrm{b}}+\rho_{\mathrm{t}}\right)$, where $\rho_{\mathrm{b}}$ is the density of the bottom layer fluid $\left(\mathrm{g} \mathrm{cm}^{-3}\right)$ and $\rho_{\mathrm{t}}$ is the density of the top layer fluid $\left(\mathrm{g} \mathrm{cm}^{-3}\right)$.

2.3.2 Dynamic sag test. The dynamic sag tendency of the drilling fluids was determined via the Viscometer Sag Shoe Test (VSST), which measures the sag tendency under dynamic conditions. The barite/WDFs and $\mathrm{Mn}_{3} \mathrm{O}_{4} / \mathrm{WDFs}$ after aging at $150{ }^{\circ} \mathrm{C}$ were continuously sheared at $100 \mathrm{rpm}$ (six-speed rotating viscometer) for $30 \mathrm{~min}$. Using a syringe with a cannula, $10 \mathrm{~mL}$ was extracted before and after shearing the sample and the weight of the fluid recorded. The dynamic sag coefficient (VSST) can be calculated according to the formula: VSST $\left(\mathrm{g} \mathrm{cm}^{-3}\right)=0.1$ $\times\left(W_{2}-W_{1}\right)$, where $W_{1}$ is the weight of $10 \mathrm{~mL}$ drilling fluid before $30 \mathrm{~min}$ of shearing at $100 \mathrm{rpm}(\mathrm{g})$ and $W_{2}$ is the weight of $10 \mathrm{~mL}$ drilling fluid after $30 \mathrm{~min}$ of shearing at $100 \mathrm{rpm}(\mathrm{g})$.

2.3.3 Static sag velocity test. Equal amounts of barite/WDFs and $\mathrm{Mn}_{3} \mathrm{O}_{4} / \mathrm{WDFs}$ were placed in test tubes and allowed to stand for $24 \mathrm{~h}$. The height $(H, \mathrm{~mm})$ of the supernatant in the test tube was recorded for different times $(t, \mathrm{~h})$, and the $H-t$ curve was plotted. The slope of the curve reflects the sag velocity of the weighting material in the drilling fluid.

\subsection{Rheology and filtration tests}

After preparing the barite/WDFs and $\mathrm{Mn}_{3} \mathrm{O}_{4} / \mathrm{WDFs}$, a MOD.1103 six-speed rotating viscometer (Qingdao Chuangmeng Instrument Technology Services Ltd., China) was used for the rheology measurements. The liquid was poured into the sample cup up to the marked line and the readings from $600 \mathrm{rpm}$ to $3 \mathrm{rpm}$ recorded, which were used to calculate the rheological parameters, such as the apparent viscosity (AV), plastic viscosity (PV) and yield point (YP). The $3 \mathrm{rpm}$ reading after $10 \mathrm{~s}$ and $10 \mathrm{~min}$ was recorded as the gel strength of the drilling fluid. The rheological parameters were calculated from the value of $\varnothing 600$ (reading of viscosity at $600 \mathrm{rpm}$ ) and $\varnothing 300$ (reading of viscosity at $300 \mathrm{rpm}$ ) using the following formulas:

$$
\begin{gathered}
\text { Apparent viscosity (AV) }=0.5 \varnothing 600(\mathrm{mPa} \mathrm{s}) \\
\text { Plastic viscosity (PV) }=\varnothing 600-\varnothing 300(\mathrm{mPa} \mathrm{s}) \\
\text { Yield point }(\mathrm{YP})=0.5(2 \varnothing 300-\varnothing 600)(\mathrm{Pa})
\end{gathered}
$$

The API filtration volume of the drilling fluid was determined with an MOD.SD6A medium-pressure filtration apparatus (Qingdao Haitongda Dedicated Instrument Factory, China). At room temperature, $300 \mathrm{~mL}$ drilling fluid was poured into filtration tanks and the filtration volume was measured within 30 min after passing through a filter paper with a diameter of $9 \mathrm{~cm}$ at a pressure of $0.69 \mathrm{MPa}$. Then the drilling fluid was poured into an aging tank and hot rolled at a specific temperature $\left(80^{\circ} \mathrm{C}, 120^{\circ} \mathrm{C}\right.$, and $\left.150{ }^{\circ} \mathrm{C}\right)$ in a GW300-type variable frequency rolling furnace (Qingdao Tongchun Machinery Factory, China). The rolling time was fixed at $16 \mathrm{~h}$. Rheology and filtration tests were performed before and after the thermal aging experiments.

\subsection{Characterization of filter cakes deposited from barite/ WDFs and $\mathrm{Mn}_{3} \mathrm{O}_{4} /$ WDFs}

The filter cakes of barite and $\mathrm{Mn}_{3} \mathrm{O}_{4}$ were characterized using scanning electron microscopy (SEM, JSM7401, JEOL, Japan). After each filtration test was completed, the filter cakes were flushed to remove the false filter cake with deionized water and the thickness of the fresh filter cake was also measured. Then, the filter cakes were dried, and the cross section of the filter cake was metal sprayed as an observation surface. The permeability $(K)$ of a fresh filter cake was calculated according to Darcy's law:

$$
K=Q \mu L /(A \Delta p t)
$$

where $Q$ is the filtration volume in $30 \mathrm{~min}$ of drilling fluid (ml), $\mu$ is the viscosity of fluid at $25{ }^{\circ} \mathrm{C}(\mathrm{mPa} \mathrm{s}), L$ is the thickness of the filter cake (cm), $\Delta p$ is the total pressure drop (0.69 MPa), and $A$ is the cross-sectional area to fluid flow ( 45.8 $\left.\mathrm{cm}^{2}\right)$.

\subsection{Characterization of API barite and micro-manganese $\left(\mathrm{Mn}_{3} \mathrm{O}_{4}\right)$}

2.6.1 Particle size analysis. The particle size distribution (PSD) of barite and $\mathrm{Mn}_{3} \mathrm{O}_{4}$ was determined using a particle size analyzer (Mastersizer 2000, Malvern, UK) with the particle size ranging from 0.01 to $1000 \mu \mathrm{m}$. 
2.6.2 Scanning electron microscopy (SEM). The morphology of barite and $\mathrm{Mn}_{3} \mathrm{O}_{4}$ was observed using a scanning electron microscope (SEM, JSM7401, JEOL, Japan). A small amount of barite and $\mathrm{Mn}_{3} \mathrm{O}_{4}$ particles was adhered to conductive tape and then metal sprayed for $2 \mathrm{~min}$.

2.6.3 X-ray photoelectron spectroscopy (XPS). X-ray photoelectron spectroscopy (XPS, PHI Quantera II, Ulvac-Phi Inc. Japan) was used to analyze the elemental composition of barite and $\mathrm{Mn}_{3} \mathrm{O}_{4}$. The powdered barite and $\mathrm{Mn}_{3} \mathrm{O}_{4}$ were tableted using aluminum foil, double-sided tape and a hydraulic press and then tested.

2.6.4 Surface tension test. The surface tension $(T)$ of barite and $\mathrm{Mn}_{3} \mathrm{O}_{4}$ in different liquids was analyzed using an automatic tension meter (JK99C, POWEREACH, China) with a platinum ring. Distilled water was prepared, and $0.5 \mathrm{wt} \%$ hydroxyethyl starch solution and $0.1 \mathrm{wt} \%$ polyacrylamide (PAM) solution and $0.5 \mathrm{wt} \%$ barite and $\mathrm{Mn}_{3} \mathrm{O}_{4}$ were added to the distilled water, to obtain the starch solution and PAM solution, respectively, and stirred uniformly. For the convenience of testing, $0.5 \mathrm{wt} \%$ of polymer RHPT-1 as a viscosifier was added to the WDFs to improve the viscosity of the drilling fluid, which can avoid rapid sag of barite. Then, $10 \mathrm{wt} \%$ of barite and $10 \mathrm{wt} \% \mathrm{Mn}_{3} \mathrm{O}_{4}$ were add to the new WDFs, respectively. The surface tension $\left(T, \mathrm{~N} \mathrm{~m}^{-1}\right)$ of the above four fluid samples was tested.

2.6.5 Zeta potential measurements. Suspensions of $0.5 \mathrm{wt} \%$ of barite and $\mathrm{Mn}_{3} \mathrm{O}_{4}$ were prepared separately using distilled water, and the $\mathrm{pH}$ value was adjusted from 7 to 9 using $\mathrm{NaOH}$. Zeta potential measurements were performed using a Zeta potentiometer (ZS90, Malvern Instrument, United Kingdom).

2.6.6 Friction coefficient test. The coefficient of friction of the barite/WDFs and $\mathrm{Mn}_{3} \mathrm{O}_{4}$ /WDFs was tested using an EP Lubricity Tester (Fann 21200, Houston, Texas U.S.A). The drilling fluid prepared for the surface tension test was poured into the sample cup, the friction block was installed, and the torque was adjusted to 0 under a rotating speed of $60 \mathrm{rpm}$. The pallet of the sample cup raised to completely immerse the friction block in the fluid to be tested. Then it was rapidly pressurized to $16.95 \mathrm{~N} \mathrm{~m}$ and the torque reading $(T)$ was recorded while the instrument turned for 5 minutes. The instrument was first calibrated with clean water to obtain the correction factor $(f)$. The sample fluids (density ranging from $1.1 \mathrm{~g} \mathrm{~cm}^{-3}$ to $1.6 \mathrm{~g} \mathrm{~cm}^{-3}$ ) were then tested and the friction coefficient $(F)$ of the sample fluid was calculated according to the formula:

$$
F=T \times f / 100
$$

\section{Results and discussions}

\subsection{Property of sag stability}

3.1.1 Static sag. Static sag refers to the sag of weighting materials when the circulation of drilling fluid is stopped. According to the calculation of static sag, no sag occurs when the SF is equal to 0.50 . Acceptable SF should between 0.50 to
0.53. ${ }^{30}$ However, when SF exceeds 0.53, the phenomenon of static sag becomes apparent. Thus, drilling fluids with an SF exceeding 0.53 are not recommended according to the API standard. ${ }^{37}$ The static sag factor of the barite/WDFs and $\mathrm{Mn}_{3} \mathrm{O}_{4} /$ WDFs at densities ranging from $1.8 \mathrm{~g} \mathrm{~cm}^{-3}$ to $2.8 \mathrm{~g} \mathrm{~cm}^{-3}$ is shown in Fig. 2. With an increase in the density of the WDFs, the SF decreased for both the barite/WDFs and $\mathrm{Mn}_{3} \mathrm{O}_{4} /$ WDFs. This was because the solid phase content in the WDFs increased dramatically and the binding effect between particles was enhanced. Compared with the $\mathrm{Mn}_{3} \mathrm{O}_{4} / \mathrm{WDFs}$, the $\mathrm{SF}$ of the barite/WDFs with a density ranging from $1.8 \mathrm{~g} \mathrm{~cm}^{-3}$ to $2.6 \mathrm{~g} \mathrm{~cm}^{-3}$ clearly exceeded the safety range of 0.53 . Although the SF of the barite/WDFs with a density of $2.8 \mathrm{~g} \mathrm{~cm}^{-3}$ was only 0.507 , after standing for $24 \mathrm{~h}$, the fluid had completely lost fluidity and consolidated into a block (Fig. 3). On the contrary, the $\mathrm{SF}$ of the $\mathrm{Mn}_{3} \mathrm{O}_{4} / \mathrm{WDFs}$ was maintained within 0.53 , and even after the density increased to $2.8 \mathrm{~g} \mathrm{~cm}^{-3}$, it still maintained fluidity after standing for $24 \mathrm{~h}$ (Fig. 3). Thus, these results confirm that $\mathrm{Mn}_{3} \mathrm{O}_{4}$ has better static sag stability than barite.

3.1.2 Static sag velocity. The sagging of the weighting particles in the drilling fluids resulted in solid-liquid separation, exhibiting a clear boundary between the supernatant and solid phase particles, as shown in Fig. 3. During the same standing time, the higher the height of the supernatant, the faster the sag velocity of the weighting material, and the slope of the curve reflected the sag velocity of the weighting material. Fig. 4a shows the $H-t$ curve (supernatant height $v s$. standing time) of the barite/WDFs at different densities, and Fig. $4 \mathrm{~b}$ shows the $H-t$ curves of the $\mathrm{Mn}_{3} \mathrm{O}_{4} /$ WDFs. It can be seen in Fig. 4a that the sag velocity of barite slowed down as the standing time increased. At the same time, the low-density barite/WDFs sagged faster than the high-density barite/WDFs, and the final supernatant was also higher, which indicated greater sagging. This is because as the density increased, the content of barite in the barite/WDFs increased significantly, resulting in a decrease in free water content in the barite/WDFs. Eventually, when the density reached $2.8 \mathrm{~g} \mathrm{~cm}^{-3}$, there was almost no free water, causing the barite/WDFs to completely

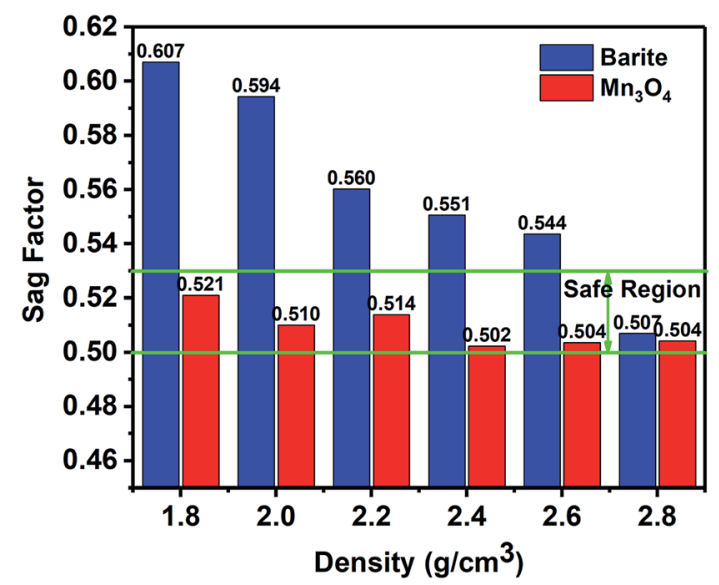

Fig. 2 Static sag factor of the barite/WDFs and $\mathrm{Mn}_{3} \mathrm{O}_{4} /$ WDFs at different densities. 


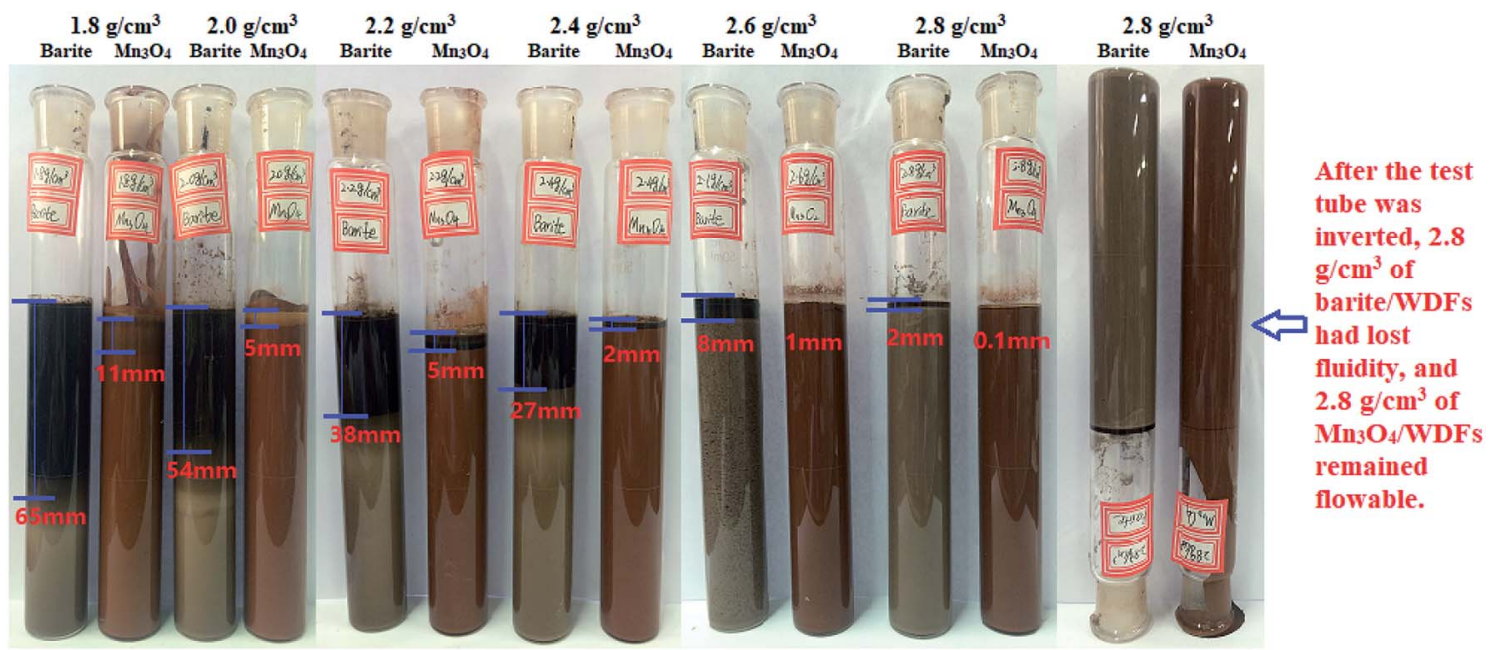

Fig. 3 Different densities of the barite/WDFs and $\mathrm{Mn}_{3} \mathrm{O}_{4} / \mathrm{WDFs}$ after $24 \mathrm{~h}$ of standing.

lose fluidity. However, the $\mathrm{Mn}_{3} \mathrm{O}_{4} / \mathrm{WDFs}$ with a density of $2.8 \mathrm{~g} \mathrm{~cm}^{-3}$ still had fluidity, which indirectly indicates that the $\mathrm{Mn}_{3} \mathrm{O}_{4}$ particles were superior to the barite in suspension performance in drilling fluid. This is also consistent with the findings in the literature ${ }^{11}$ and with the static sag test, which indicated that the static sag stability of barite was worse than that of $\mathrm{Mn}_{3} \mathrm{O}_{4}$.

3.1.3 Dynamic sag. The VSST value was used to characterize the magnitude of the dynamic sag. A VSST value of $0.12 \mathrm{~g} \mathrm{~cm}^{-3}$ or less implies a drilling fluid with the minimal sagging tendency, while a VSST value above $0.19 \mathrm{~g} \mathrm{~cm}^{-3}$ indicates the beginning of a possible sag problem. ${ }^{3}$ The dynamic sag test required continuous shearing of the drilling fluid for $30 \mathrm{~min}$ using a six-speed rotating viscometer. However, after $30 \mathrm{~min}$ of shearing, the barite had formed a precipitate having a thickness of about $10 \mathrm{~mm}$ at the bottom of the sample cup, and thus it was no longer possible to use a syringe to suck the fluid from the collection well of the sag shoe for testing. After aging at $150{ }^{\circ} \mathrm{C}$, the barite/WDFs completely lost fluidity and solidified into a block (Fig. 5), but it could recover fluidity after high-speed stirring. This was also a strong evidence that barite had rapidly sagged during drilling fluid shearing. The $\mathrm{Mn}_{3} \mathrm{O}_{4} / \mathrm{WDFs}$ exhibited the opposite trend. As the density of drilling fluid

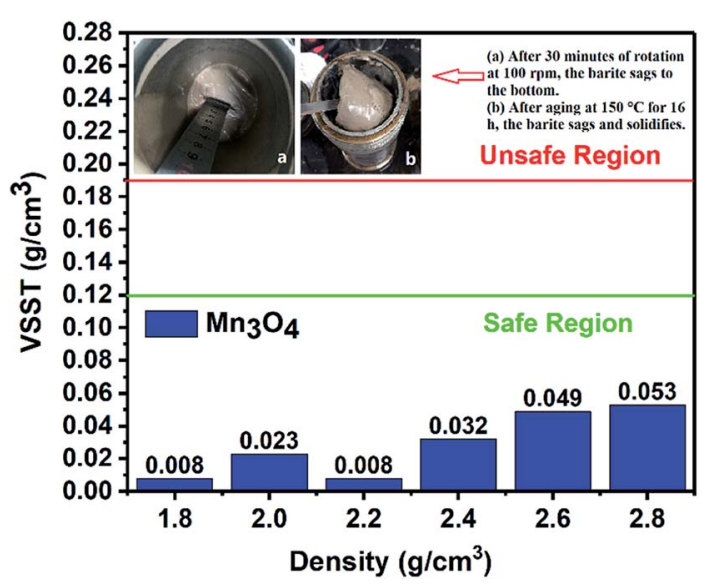

Fig. 5 Dynamic sag test for the barite/WDFs and $\mathrm{Mn}_{3} \mathrm{O}_{4} /$ WDFs at different densities.
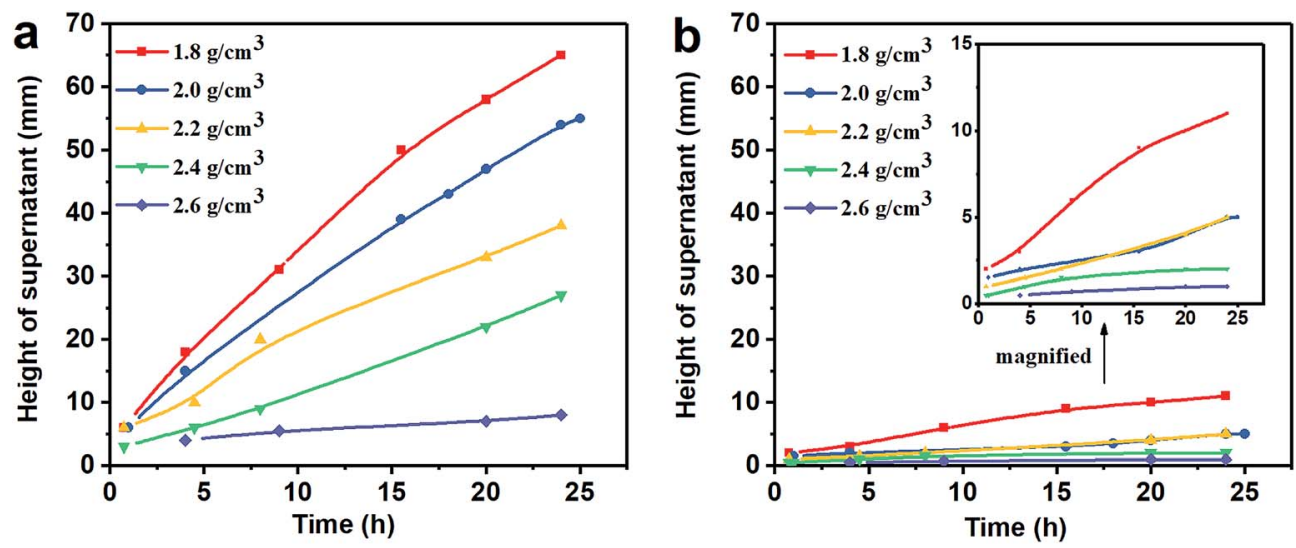

Fig. 4 Variation in supernatant height of different densities of drilling fluid with standing time. (a) Barite/WDFs and (b) $\mathrm{Mn}_{3} \mathrm{O}_{4} / \mathrm{WDFs}$. 
increased, the VSST value of $\mathrm{Mn}_{3} \mathrm{O}_{4} /$ WDFs increased. Even when the density increased to $2.8 \mathrm{~g} \mathrm{~cm}^{-3}$, the VSST value was only $0.053 \mathrm{~g} \mathrm{~cm}^{-3}$, which is much lower than the safety value of $0.12 \mathrm{~g} \mathrm{~cm}^{-3}$. Therefore, combined with the static sag test results and the $H-t$ curve, the sag stability of $\mathrm{Mn}_{3} \mathrm{O}_{4}$ in the drilling fluid was significantly better than that of barite.

\subsection{Rheological properties}

3.2.1 Apparent viscosity. The apparent viscosity of the barite/WDFs and $\mathrm{Mn}_{3} \mathrm{O}_{4} / \mathrm{WDFs}$ is shown in Fig. 6. The apparent viscosity of the barite/WDFs increased rapidly with an increased in density. The same growth trend was observed for the barite/ WDFs at different aging temperatures. When the density exceeded $2.4 \mathrm{~g} \mathrm{~cm}^{-3}$, the apparent viscosity of the barite/WDFs at room temperature was too large to test, which exceeded the range of the six-speed rotating viscometer. It was demonstrated that barite increased the apparent viscosity of the drilling fluid, which seriously affects the drilling process because a too large apparent viscosity of the drilling fluid will lead to difficulties in pumping, lowering of the drilling rate, large cyclic pressure consumption, high total pump pressure, vulnerability to gas intrusion, and formation of excessive mud cake. Compared with the fine round $\mathrm{Mn}_{3} \mathrm{O}_{4}$ particles, the barite particles are large and irregular, and thus they collide and rub more frequently in the drilling fluid, resulting in the AV of the barite/WDFs being much larger than that of the $\mathrm{Mn}_{3} \mathrm{O}_{4} /$ WDFs. The dramatically increased apparent viscosity of the barite/WDFs also explain the slower sag velocity and lower SF with a high density (Fig. 2-4). On the contrary, even when the density of the $\mathrm{Mn}_{3} \mathrm{O}_{4} /$ WDFs increased to $3.0 \mathrm{~g} \mathrm{~cm}^{-3}$, the apparent viscosity was still within $60 \mathrm{mPa} \mathrm{s}$, which was significantly lower than the apparent viscosity of the barite/WDFs.

3.2.2 Plastic viscosity. Plastic viscosity (PV) represents the viscosity of mud when extrapolated to infinite shear rate. Generally, a drilling fluid with a high PV is difficult to pump, and thus not suitable for drilling operations. ${ }^{38}$ In the API specification, the recommended value for plastic viscosity is 8$35 \mathrm{mPa} \mathrm{s.}{ }^{30}$ It was obvious that the barite/WDFs had a high plastic viscosity and a very fast growth rate at a high density of more than $2.2 \mathrm{~g} \mathrm{~cm}^{-3}$ (Fig. 7a). When the density of the barite/ WDFs was $2.4 \mathrm{~g} \mathrm{~cm}^{-3}$, the plastic viscosity before and after aging at $80^{\circ} \mathrm{C}, 120^{\circ} \mathrm{C}$, and $150{ }^{\circ} \mathrm{C}$ increased to $108,79,98$, and $74 \mathrm{mPa}$ s, respectively. However, with an increase in density, the plastic viscosity of the $\mathrm{Mn}_{3} \mathrm{O}_{4} /$ WDFs slowly increased, and it could be all kept within a reasonable range of values below 40 $\mathrm{mPa} s$ (Fig. 7b). One of the main factors affecting plastic viscosity is the solid phase content in the drilling fluid. ${ }^{29,39}$ The $\mathrm{Mn}_{3} \mathrm{O}_{4}$ particles have a high density, and thus the amount of micro-manganese required when the drilling fluid needs to weighted is lower than that of barite; therefore, the solid phase content in the $\mathrm{Mn}_{3} \mathrm{O}_{4} / \mathrm{WDFs}$ is lower than that of the barite/ WDFs. Therefore, the plastic viscosity of the $\mathrm{Mn}_{3} \mathrm{O}_{4} /$ WDFs increased slowly. These phenomena suggest that plastic viscosity can be controlled effectively by $\mathrm{Mn}_{3} \mathrm{O}_{4}$.

3.2.3 Gel strength. Gel strength is the strength of the drilling fluid to form a grid structure at standing, which reflects the ability of the drilling fluid to suspend cuttings or weighting materials while there is no circulation. ${ }^{3,38}$ The gel strength is related to the time factor and is usually measured by $10 \mathrm{~s}$ gel strength and 10 min gel strength. It can be seen from Fig. 8a that at low densities, the gel strength of the barite/WDFs was less than 0.5 $\mathrm{Pa}$, which was not conducive to suspend barite. ${ }^{29}$ However, the gel strength of the $\mathrm{Mn}_{3} \mathrm{O}_{4} /$ WDFs was higher than that of the barite/WDFs, especially at high density $\left(>2.2 \mathrm{~g} \mathrm{~cm}^{-3}\right)$. After aging at $120{ }^{\circ} \mathrm{C}$ (Fig. 8b), the gel strength of the barite/ WDFs showed little changes except the fluid with a density of $2.8 \mathrm{~g} \mathrm{~cm}^{-3}$. There was an obvious increase in gel strength of the barite/WDFs at this density, but it was still less than that of the $\mathrm{Mn}_{3} \mathrm{O}_{4} /$ WDFs. This result shows that $\mathrm{Mn}_{3} \mathrm{O}_{4}$ increased the gel strength values. In addition, the enhancement in the gel strength at a high temperature (Fig. 8b) helped in reducing the settling of solid particles under static conditions.

Thus, the above rheological property test indicates that the use of $\mathrm{Mn}_{3} \mathrm{O}_{4}$ in drilling fluid can effectively control the viscosity of the drilling fluid and increase the gel strength. However, barite cannot be used to make drilling fluid with a density
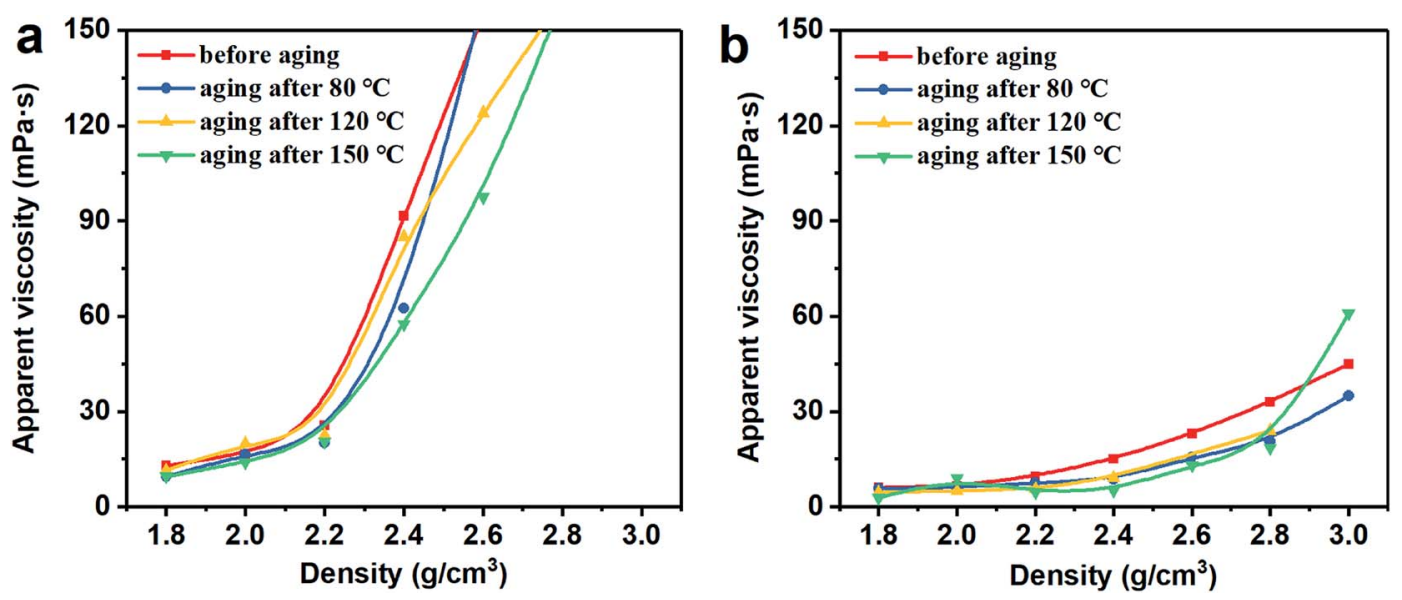

Fig. 6 Apparent viscosity of different density drilling fluids at different aging temperatures. (a) $\mathrm{Barite} / \mathrm{WDFs}$ and (b) $\mathrm{Mn}_{3} \mathrm{O}_{4} /$ WDFs. 

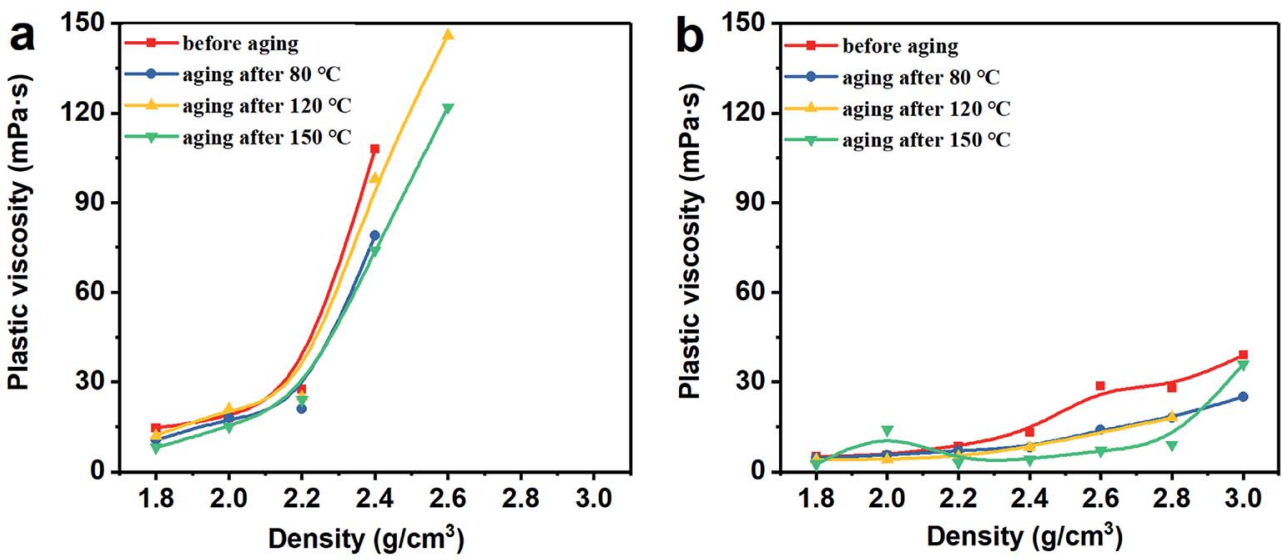

Fig. 7 Plastic viscosity of different density drilling fluids at different aging temperatures. (a) Barite/WDFs and (b) $\mathrm{Mn}_{3} \mathrm{O}_{4} / \mathrm{WDFs}$.

greater than $2.4 \mathrm{~g} \mathrm{~cm}^{-3}$. After the density of the barite/WDF exceeded $2.2 \mathrm{~g} \mathrm{~cm}^{-3}$, its rheological properties began to deteriorate rapidly and severely, after the density reached $2.4 \mathrm{~g} \mathrm{~cm}^{-3}$, and the basic performance requirements of the drilling fluid could not be satisfied.

\subsection{Filtration properties}

The fluid loss and well building property refer to the free water in the drilling fluid entering the formation, and the solid phase particles in the drilling fluid adhering to the well to form a filter cake during the filtration process. ${ }^{5}$ A too large filtrate volume will result in swelling and collapsing of the rock, which is water sensitive, and a thick filter cake will lead to accidents such as tight holes and stuck pipes. The API recommended value is 3 to $15 \mathrm{~mL} .^{40}$ The filtration volume of the barite/WDFs and $\mathrm{Mn}_{3} \mathrm{O}_{4} /$ WDFs is shown in Fig. 9. With an increased in density, the filtration volume of the barite/WDFs and $\mathrm{Mn}_{3} \mathrm{O}_{4} / \mathrm{WDFs}$ increased slowly. There were slight changes in the filtration volume of the barite/WDFs at different aging temperatures (Fig. 9a). The biggest filtration volume in all the barite/WDFs was $15 \mathrm{~mL}$, which is acceptable with the API standard. However, the filtration volume of the $\mathrm{Mn}_{3} \mathrm{O}_{4} / \mathrm{WDFs}$ was about two times that of the barite/WDFs (Fig. 9b). The filtration volume increased obviously after the aging experiments. After aging at $150{ }^{\circ} \mathrm{C}$, the filtration volume of the $\mathrm{Mn}_{3} \mathrm{O}_{4} / \mathrm{WDFs}$ with densities ranging from 1.8 to $2.8 \mathrm{~g} \mathrm{~cm}^{-3}$ increased from 9.7 , $13.5,15.5,17,17.1$, and $19 \mathrm{~mL}$ before aging to 18.6, 20, 22, 20, 20.2 , and $30 \mathrm{~mL}$, respectively. Obviously, as the amount of $\mathrm{Mn}_{3} \mathrm{O}_{4}$ increased, the filtration volume of the $\mathrm{Mn}_{3} \mathrm{O}_{4} /$ WDFs gradually increased. According to Darcy's law, the filtration volume of unit time is directly related to the permeability and the thickness of the filter cake and the viscosity of the fluid. Thus, one of the keys to minimize the fluid loss in drilling fluids is to improve the quality of the filter cake. In engineering, it is generally required to obtain a thin and tight filter cake, that is, a filter cake with low permeability and small thickness. Subsequently, the characteristics of the filter cakes were considered.

The fresh filter cakes of the barite/WDFs and $\mathrm{Mn}_{3} \mathrm{O}_{4} / \mathrm{WDFs}$ with a density of $2.2 \mathrm{~g} \mathrm{~cm}^{-3}$ are shown in Fig. 10. It can be seen that the filter cake of the barite/WDFs was thicker and that of the $\mathrm{Mn}_{3} \mathrm{O}_{4} / \mathrm{WDFs}$ was thinner. According to statistics, the average thickness of the filter cake of the different density barite/WDFs was about $8 \mathrm{~mm}$, while that of $\mathrm{Mn}_{3} \mathrm{O}_{4} / \mathrm{WDFs}$ was only $1.5 \mathrm{~mm}$. However, only observing the surface of the filter
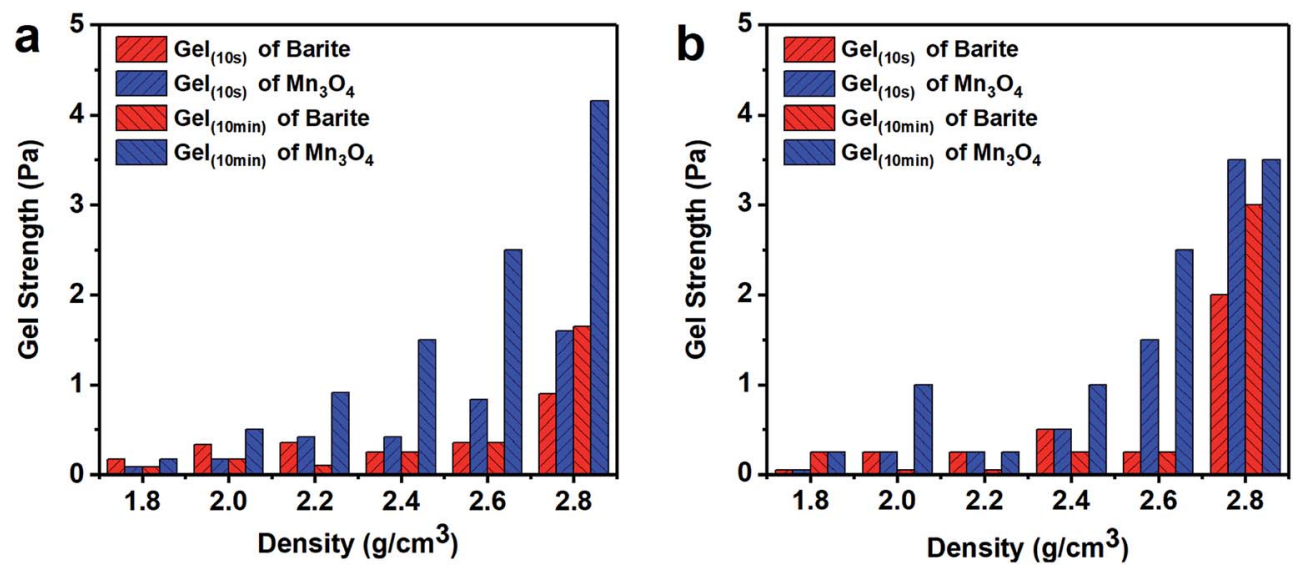

Fig. 8 Gel strength of different density barite/WDFs and $\mathrm{Mn}_{3} \mathrm{O}_{4} /$ WDFs. (a) Before aging and (b) after aging at $120^{\circ} \mathrm{C}$. 

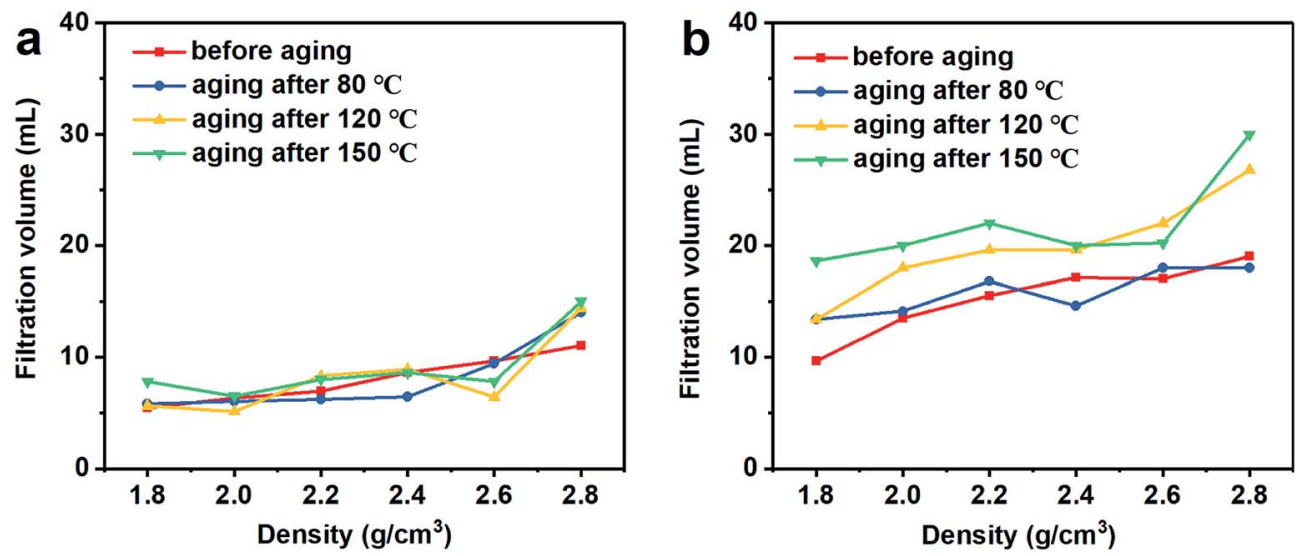

Fig. 9 Filtration volume of the drilling fluid with different densities at different aging temperatures. (a) $\mathrm{Barite} / \mathrm{WDFs}$ and (b) $\mathrm{Mn}_{3} \mathrm{O}_{4} / \mathrm{WDFs}$.

cake cannot be used for the direct comparison of the differences in compactness of the filter cakes. Under the pressure of the API filtrate test, the particles in the tested fluid sagged on the filter paper and then formed a filter cake. The inter-filling of the small particles with the large particles reduces the water passage of the filter cake. It is well known that the less cracks in the filter cake, the smaller the permeability of the filter cake. The difference in the formation of filter cake between the barite and $\mathrm{Mn}_{3} \mathrm{O}_{4}$ particles can be clearly seen in Fig. 11. Since the barite sagged quickly in the drilling fluid, a large amount of barite was continuously deposited on the filter cake, resulting in the ultimate formation of a thick cake. The sharp and uneven shape of the particles caused the accumulation of particles not to be compact and there were many cracks between the particles (Fig. 11a). However, the $\mathrm{Mn}_{3} \mathrm{O}_{4}$ particles had a slow sag rate and good suspension performance in the drilling fluid. Therefore, after a small portion of the particles formed a filter cake, the remaining particles were still suspended in the drilling fluid, and thus the final filter cake was thin. Simultaneously, the spherical and uniform-sized $\mathrm{Mn}_{3} \mathrm{O}_{4}$ particles were more densely packed with each other, and there were few cracks between the particles (Fig. 11b). The above filter cake formation analysis was further confirmed by SEM. Fig. 12 shows the microstructures of the dried filter cakes in Fig. 10. As shown in Fig. 12a, the barite was loosely packed, and obvious pores and cracks of about 10 $\mu \mathrm{m}$ can be seen, which are favorable for the penetration of the filtrate. However, the filter cake formed by $\mathrm{Mn}_{3} \mathrm{O}_{4}$ was significantly denser. The filter cake magnified 5000 times in Fig. 12b2 was made up of many layers of fine $\mathrm{Mn}_{3} \mathrm{O}_{4}$ particles, and no pores and cracks larger than that in the filter cake of the barite/ WDFs were found. This indicates that $\mathrm{Mn}_{3} \mathrm{O}_{4}$ can form a much denser filter cake than barite. To further verify this conclusion, the permeability $(K)$ of the filter cakes of the barite/WDFs and $\mathrm{Mn}_{3} \mathrm{O}_{4} / \mathrm{WDFs}$ with different densities was calculated according to Darcy's law, the results are shown in Fig. 13. It was proven that the filter cake formed by barite had a permeability greater than that of $\mathrm{Mn}_{3} \mathrm{O}_{4}$. Moreover, as the density increased, the filter cake permeability of the barite/WDFs increased rapidly. Under a high density of $2.6 \mathrm{~g} \mathrm{~cm}^{-3}$, the permeability of the barite/WDFs filter cake was almost six times larger than that of $\mathrm{Mn}_{3} \mathrm{O}_{4}$. The same phenomena were observed in the filter cake of the drilling fluid after aging (Fig. 13b). Both the SEM micrographs and the calculated permeability confirmed that the quality of the filter cake formed by $\mathrm{Mn}_{3} \mathrm{O}_{4}$ was better than that of barite.

However, this conclusion is contrary to the results of the fluid loss test. Why was the filtration volume of the barite/WDFs significantly lower than that of the $\mathrm{Mn}_{3} \mathrm{O}_{4} / \mathrm{WDFs}$ ? According to

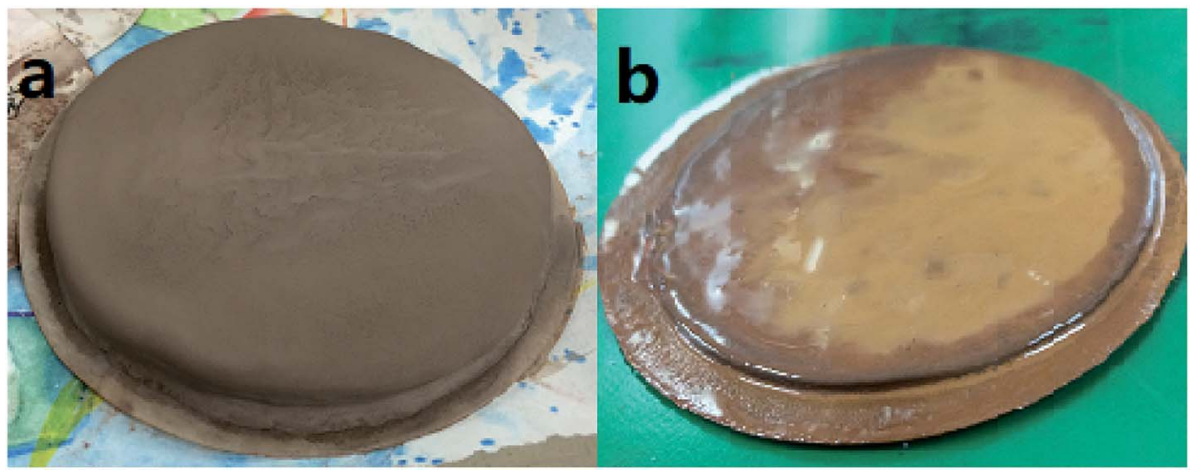

Fig. 10 Fresh filter cakes of drilling fluid with a density of $2.2 \mathrm{~g} \mathrm{~cm}^{-3}$. (a) Barite/WDFs and (b) $\mathrm{Mn}_{3} \mathrm{O}_{4} /$ WDFs. 

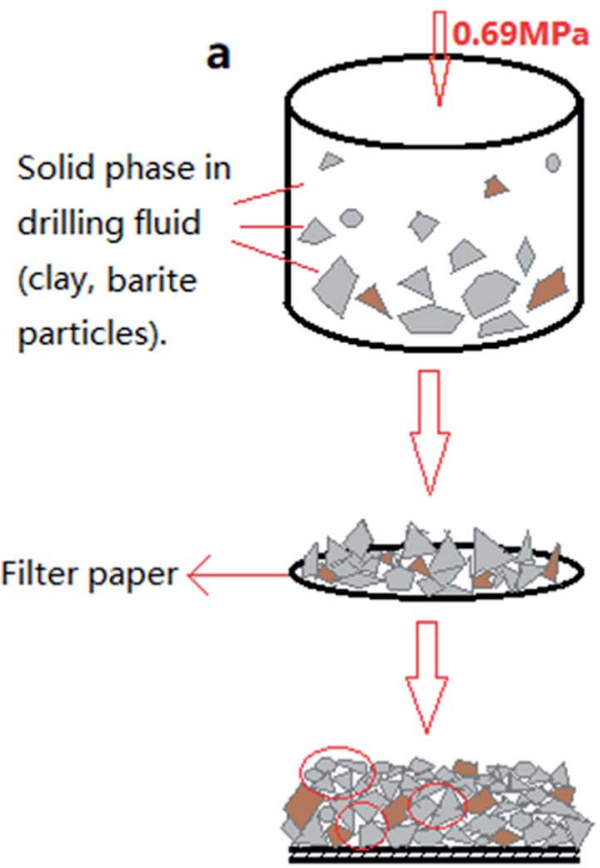

Cross-sectional

view of filter cake

b

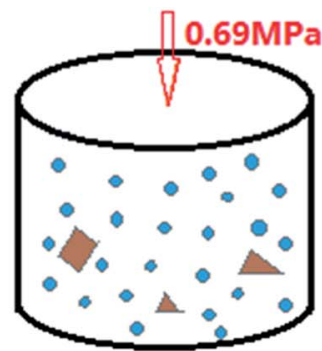

\section{The formation of}

filter cake
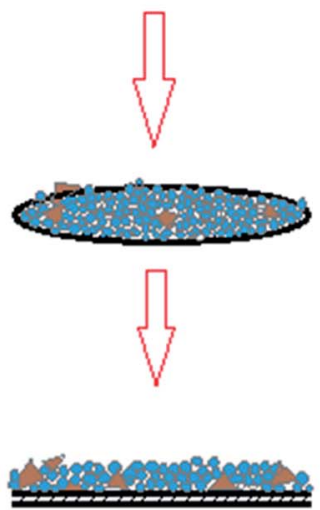

\section{Clay $\quad \triangle \Delta \diamond \circ$ Barite $\because \mathrm{Mn}_{3} \mathrm{O}_{4}$}

Fig. 11 Schematic diagram of the particle packing in the filter cake. (a) Barite/WDFs and (b) $\mathrm{Mn}_{3} \mathrm{O}_{4} /$ WDFs.

previous studies, the filtration performance of drilling fluids is primarily affected by the viscosity of the drilling fluid and the characteristics of the filter cake. ${ }^{41,42}$ High viscosity and low filter cake permeability help to decelerate the filtration rate and reduce the filtrate volume. ${ }^{43}$ In the barite/WDFs, the viscosity increased rapidly with an increase in drilling fluid density,

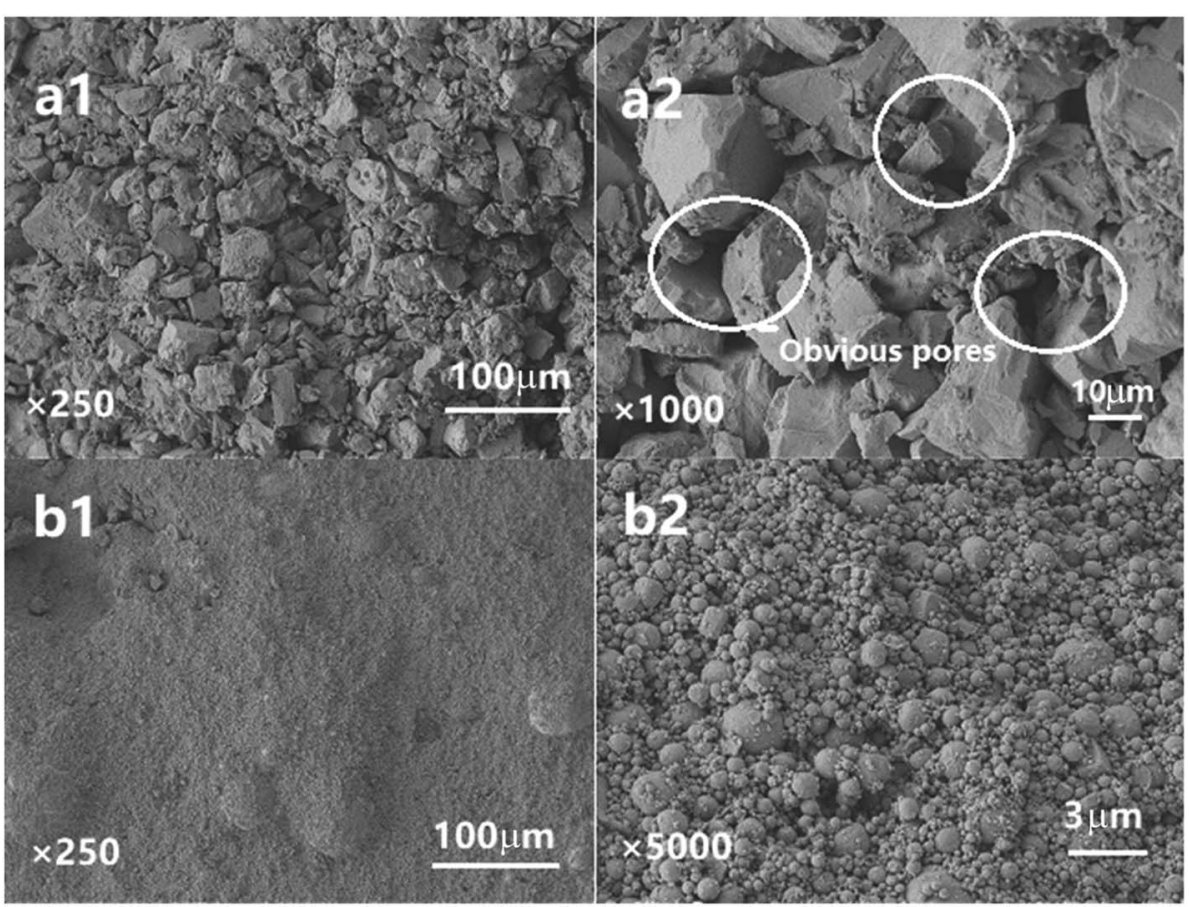

Fig. 12 SEM micrographs of the dried filter cakes in Fig. 10. (a1) Filter cake of barite/WDFs magnified by 250 times, (a2) filter cake of the barite/ WDFs magnified by 100 times, (b1) filter cake of the $\mathrm{Mn}_{3} \mathrm{O}_{4} /$ WDFs magnified by 250 times and (b2) filter cake of $\mathrm{Mn}_{3} \mathrm{O}_{4} / \mathrm{WDFs}$ magnified by 5000 times. 

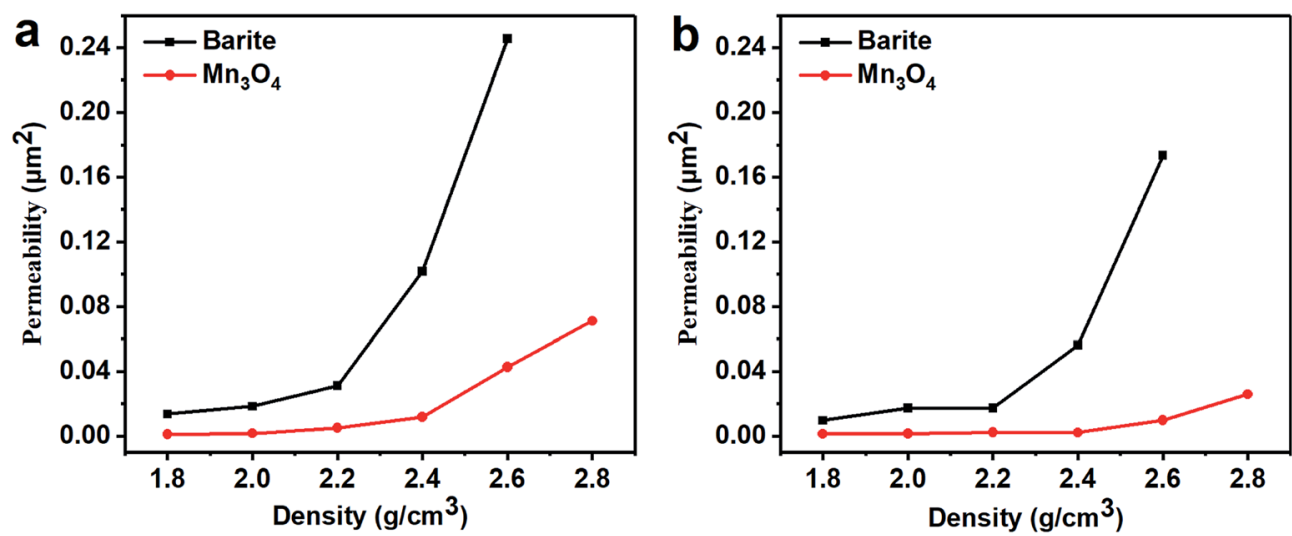

Fig. 13 Permeability of the drilling fluid filter cakes with different densities. (a) Before aging and (b) after aging at $80{ }^{\circ} \mathrm{C}$.

which is the main reason for its improved filtration performance. The increase in viscosity significantly reduced the filtration rate, while the increase in permeability accelerated the filtration rate, which both cancelled each other out. In the barite/WDFs, the effect of viscosity was greater than the effect of permeability, and simultaneously, the sag of barite formed an extremely thick filter cake, thus the filtrate volume of barite/ WDFs was low. However, in the $\mathrm{Mn}_{3} \mathrm{O}_{4} /$ WDFs, the improvement of the filtration performance of the permeability was not enough to offset the influence of other factors, so the filtrate volume was higher than the barite/WDFs. However, the thick filter cake of the barite/WDFs may lead to drilling accidents such as stuck pipes and pumping difficulties, which are not desirable in engineering practice.
To investigate the availability of $\mathrm{Mn}_{3} \mathrm{O}_{4}$ in the actual drilling process, the sulfonation drilling fluid system (Table 1) commonly used in drilling sites was used to evaluate the rheology and fluid loss of the drilling fluid after it was weighted by $\mathrm{Mn}_{3} \mathrm{O}_{4}$. The performance of the $\mathrm{Mn}_{3} \mathrm{O}_{4}$-weighted drilling fluid before and after aging at $150^{\circ} \mathrm{C}$ is shown in Tables 2 and 3 . It can be seen from Tables 2 and 3 that the $\mathrm{Mn}_{3} \mathrm{O}_{4}$-weighted drilling fluid effectively improved the apparent viscosity, yield point and gel strength of the drilling fluid, both before and after aging, which indicates that the suspension and carrying capacity of the drilling fluid were enhanced. For the fluid loss performance, the fluid loss of the drilling fluid after it was weighted by $\mathrm{Mn}_{3} \mathrm{O}_{4}$ increased from 4.6 to $8 \mathrm{~mL}$ before aging and from 4.8 to $8.2 \mathrm{~mL}$ after aging at $150{ }^{\circ} \mathrm{C}$. Although it increased

Table 1 Formulation of the weighted and non-weighted sulfonated drilling fluids

\begin{tabular}{llll}
\hline Product & Function & $\begin{array}{l}\text { Non-weighted } \\
\left(\mathrm{SG}=1 \mathrm{~g} \mathrm{~cm}^{-3}\right)\end{array}$ & $\begin{array}{l}\text { Weighted (SG } \\
\left.=2.4 \mathrm{~g} \mathrm{~cm}^{-3}\right)\end{array}$ \\
\hline Water & Base liquid & $384 \mathrm{~mL}$ & $384 \mathrm{~mL}$ \\
Bentonite & Viscosifier \& filtration control & $16 \mathrm{~g}$ & $16 \mathrm{~g}$ \\
$\mathrm{Na}_{2} \mathrm{CO}_{3}$ & Dispersed bentonite & $1 \mathrm{~g}$ & $1 \mathrm{~g}$ \\
$\mathrm{NaOH}$ & Adjust mud pH & $0.8 \mathrm{~g}$ & $0.8 \mathrm{~g}$ \\
$\mathrm{~K}-\mathrm{PAM}$ & Flocculant & $1.6 \mathrm{~g}$ & $1.6 \mathrm{~g}$ \\
$\mathrm{RHPT}-2$ & Polymer fluid loss additive & $0.4 \mathrm{~g}$ & $0.4 \mathrm{~g}$ \\
$\mathrm{DS}-302$ & Viscosity reducer & $2 \mathrm{~g}$ & $2 \mathrm{~g}$ \\
$\mathrm{RHJ}-1$ & Plugging agent & $10 \mathrm{~g}$ \\
$\mathrm{SMC}$ & Fluid loss additive & $12 \mathrm{~g}$ \\
$\mathrm{SPNH}$ & Fluid loss additive & $12 \mathrm{~g}$ \\
$\mathrm{KHm}$ & Fluid loss additive & $6 \mathrm{~g}$ & $10 \mathrm{~g}$ \\
$\mathrm{JM}-1$ & Lubricant & $6 \mathrm{~g}$ & $12 \mathrm{~g}$ \\
$\mathrm{Mn}_{3} \mathrm{O}_{4}$ & Adjust mud density & -
\end{tabular}

Table 2 Rheological properties and fluid loss of sulfonated drilling fluids (non-weighted and weighted) before aging

\begin{tabular}{|c|c|c|c|c|c|c|}
\hline Non-weighted & 14.5 & 10 & 4.5 & 1 & 3 & 4.6 \\
\hline Weighted & 49.5 & 36 & 13.5 & 11 & 16 & 8 \\
\hline
\end{tabular}


Table 3 Rheological properties and fluid loss of sulfonated drilling fluids (non-weighted and weighted) after aging at $150{ }^{\circ} \mathrm{C}$

\begin{tabular}{llllll}
\hline & $\mathrm{AV}(\mathrm{mPa} \mathrm{s})$ & $\mathrm{PV}(\mathrm{mPa} \mathrm{s})$ & $\mathrm{YP}(\mathrm{Pa})$ & $\mathrm{Gel}_{(10 \mathrm{~s})}$ & $\mathrm{Gel}_{(10 \mathrm{~min})}$ \\
\hline Non-weighted & 10.5 & 6 & 4.5 & 1 & 5 \\
Weighted & 38.5 & 32 & 6.5 & 5 & 4.8 \\
\end{tabular}

slightly, it was still in the field available range. Therefore, $\mathrm{Mn}_{3} \mathrm{O}_{4}$ is fully suitable for use in on-site drilling fluid systems.

\subsection{Suspension mechanism analysis}

3.4.1 Physical characteristic analysis of barite and $\mathrm{Mn}_{3} \mathrm{O}_{4}$. The elemental composition of barite and $\mathrm{Mn}_{3} \mathrm{O}_{4}$ was analyzed by XPS, and the results are shown in Table 4 . It can be seen that the barite was composed of sulfur $(\mathrm{S})$ and oxygen $(\mathrm{O})$ elements and had no impurities. In addition to manganese (Mn) and oxygen, micro-manganese also contained a small amount of lead $(\mathrm{Pb})$.

The particle size distribution of barite and $\mathrm{Mn}_{3} \mathrm{O}_{4}$ is presented in Fig. 14. The average particle size of the powder is usually represented by $d(0.5)$, which is actually the median diameter. It can be seen in Fig. 14 that the particle size of $\mathrm{Mn}_{3} \mathrm{O}_{4}$ was significantly lower than that of barite. The $d(0.5)$ of $\mathrm{Mn}_{3} \mathrm{O}_{4}$ and barite was $0.112 \mu \mathrm{m}, 18.309 \mu \mathrm{m}$, respectively. Furthermore, the particle size distribution of $\mathrm{Mn}_{3} \mathrm{O}_{4}$ was also narrower than that of barite. The micromorphology of barite and $\mathrm{Mn}_{3} \mathrm{O}_{4}$ was also very different (Fig. 15). Barite had irregular massive particles with sharp edges, but $\mathrm{Mn}_{3} \mathrm{O}_{4}$ contained regular spherical particles with no corners. Consequently, $\mathrm{Mn}_{3} \mathrm{O}_{4}$ consisted of spherical particles having an average particle diameter of only $0.1 \mu \mathrm{m}$, and barite consisted of massive particles having a sharp angular shape, and its average particle diameter was about 160 times that of $\mathrm{Mn}_{3} \mathrm{O}_{4}$. Therefore, Brownian motion of the $\mathrm{Mn}_{3} \mathrm{O}_{4}$ particles was dominant in solution, which can improve the dispersion stability of drilling fluids. ${ }^{\mathbf{4 4}}$

3.4.2 Surface properties analysis of barite and $\mathrm{Mn}_{3} \mathrm{O}_{4}$. The surface tension of barite and $\mathrm{Mn}_{3} \mathrm{O}_{4}$ in different solutions was shown in Fig. 16. The results show that the surface tension of $\mathrm{Mn}_{3} \mathrm{O}_{4}$ was always greater than that of barite, whether in starch solution, polyacrylamide (PAM) solution or drilling fluid. This indicates the larger interaction of $\mathrm{Mn}_{3} \mathrm{O}_{4}$ with the other molecules in solution.

The specific surface area of barite and $\mathrm{Mn}_{3} \mathrm{O}_{4}$ was also obtained simultaneously by particle size analysis. $\mathrm{Mn}_{3} \mathrm{O}_{4}$ had

Table 4 The elemental composition of barite and micro-manganese

\begin{tabular}{llc}
\hline & Elemental composition & Content (wt\%) \\
\hline Barite & $\mathrm{O}$ & 78.1 \\
& $\mathrm{~S}$ & 14.14 \\
& $\mathrm{Ba}$ & 7.76 \\
Micro-manganese & $\mathrm{O}$ & 66.48 \\
$\left(\mathrm{Mn}_{3} \mathrm{O}_{4}\right)$ & $\mathrm{Mn}$ & 32.95 \\
& $\mathrm{~Pb}$ & 0.57
\end{tabular}

a large specific surface area of $61.9 \mathrm{~m}^{2} \mathrm{~g}^{-1}$, which was almost 40 times that of barite of only $1.64 \mathrm{~m}^{2} \mathrm{~g}^{-1}$ (Fig. 17a). A large specific surface area represents a high surface free energy. This caused $\mathrm{Mn}_{3} \mathrm{O}_{4}$ to have a strong adsorption effect. In drilling fluid, $\mathrm{Mn}_{3} \mathrm{O}_{4}$ not only adsorbs dispersant molecules quickly, thus forming a solvation film on the surface of the $\mathrm{Mn}_{3} \mathrm{O}_{4}$ particles, but also forms physical crosslinks with drilling fluid additives such as polymer chains. Thus, the $\mathrm{Mn}_{3} \mathrm{O}_{4}$ particles had strong interaction with other molecules, which was proven by the surface tension test. Thereby, the dispersibility and suspension stability of the $\mathrm{Mn}_{3} \mathrm{O}_{4}$ particles in the drilling fluid improved. In contrast, barite had a small specific surface area, but a large particle size, so the adsorption between barite particles and other molecules in the drilling fluid was small. The larger selfweight accelerated its sag, which caused the poor suspension stability of the entire drilling fluid system. The zeta potential evaluation further demonstrated that $\mathrm{Mn}_{3} \mathrm{O}_{4}$ has better suspension stability in water than barite. The zeta potential results in water with different $\mathrm{pH}$ are shown in Fig. $17 \mathrm{~b}$. The higher the absolute value of the zeta potential, the more stable the solution system. Alkaline water-based drilling fluids help to increase the degree of hydration of clay. Thus, it is important to increase the suspension stability of the material under alkaline conditions. As presented in Fig. 17b, the zeta potential of the barite solution was $0.732 \mathrm{mV}$ when the $\mathrm{pH}$ value was 7 , while that of $\mathrm{Mn}_{3} \mathrm{O}_{4}$ was $-19.9 \mathrm{mV}$. When the $\mathrm{pH}$ value increased from 7 to 8 and 9 , the zeta potential of the barite solution was reversed from $0.732 \mathrm{mV}$ to $-8.82 \mathrm{mV}$ and $-18.5 \mathrm{mV}$, respectively. Simultaneously, the zeta potential value of the $\mathrm{Mn}_{3} \mathrm{O}_{4}$ solution also increased from $-19.9 \mathrm{mV}$ to $-23.2 \mathrm{mV}$ and $-26.2 \mathrm{mV}$, respectively. It was obvious that the absolute zeta

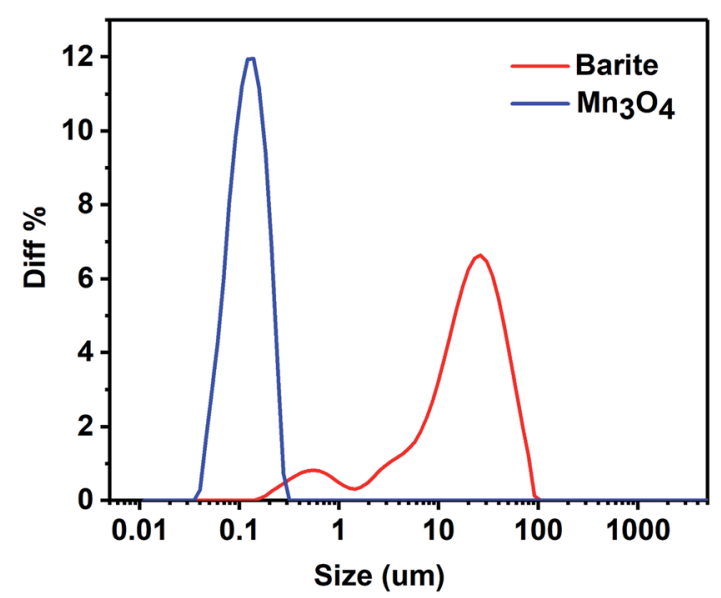

Fig. 14 Particle size distribution of barite and $\mathrm{Mn}_{3} \mathrm{O}_{4}$. 


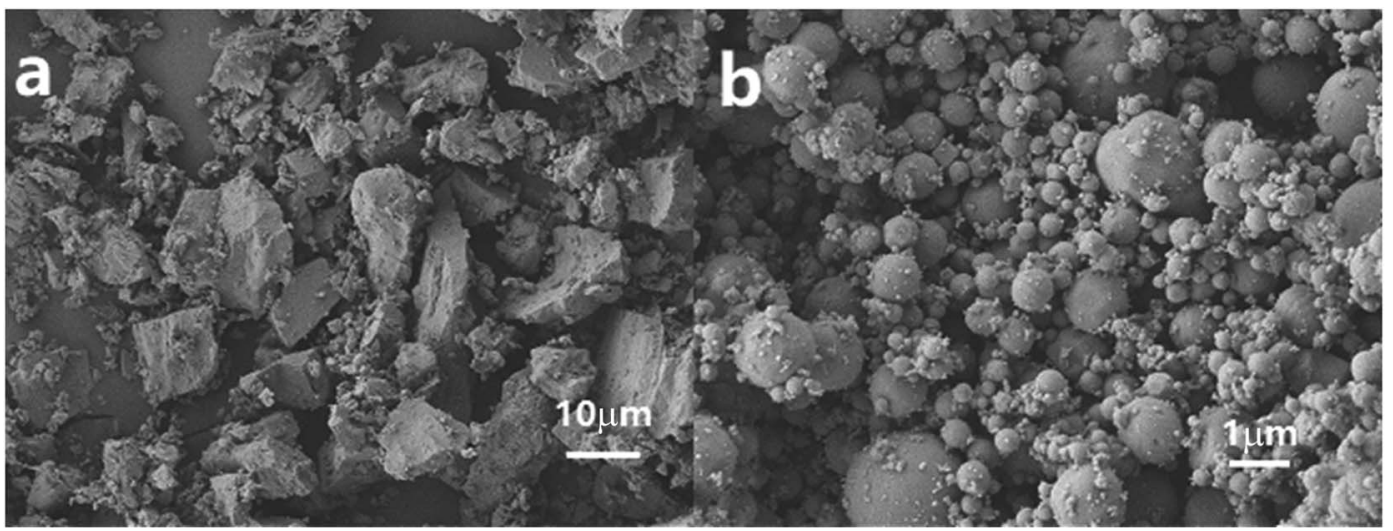

Fig. 15 Micromorphology of the particles. (a) Barite and (b) $\mathrm{Mn}_{3} \mathrm{O}_{4}$.

potential value of the $\mathrm{Mn}_{3} \mathrm{O}_{4}$ solution was always higher than that of barite, which indicates that the $\mathrm{Mn}_{3} \mathrm{O}_{4}$ particles were more electronegative in solution and had higher surface activity, and thus showed higher suspension stability.

The lubrication performance of drilling fluids has a great influence on the drilling process. High lubricity is beneficial to reduce the friction between the drill string and the well wall, reduce the torque of the rotating drill string, and ensure the smooth operation of the drilling operation. It can be seen in Fig. 18 that the friction coefficient of the $\mathrm{Mn}_{3} \mathrm{O}_{4} / \mathrm{WDFs}$ was

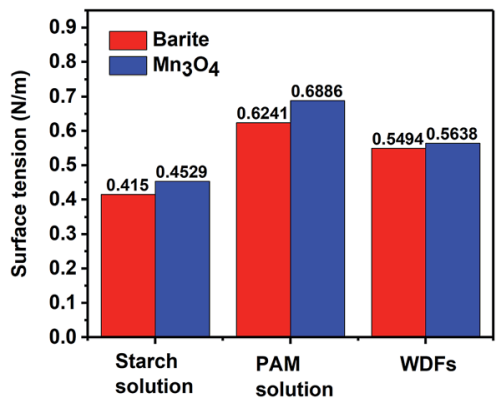

Fig. 16 Surface tension of barite and $\mathrm{Mn}_{3} \mathrm{O}_{4}$ in different solutions. lower than that of barite, which demonstrated the better lubrication performance of $\mathrm{Mn}_{3} \mathrm{O}_{4}$. The excellent lubricity is also attributed to the small and rounded morphology of the $\mathrm{Mn}_{3} \mathrm{O}_{4}$ particles. The spherical shape contributed to the sliding between the particles, which reduced the friction between the particles compared to the sharp bulk of barite.

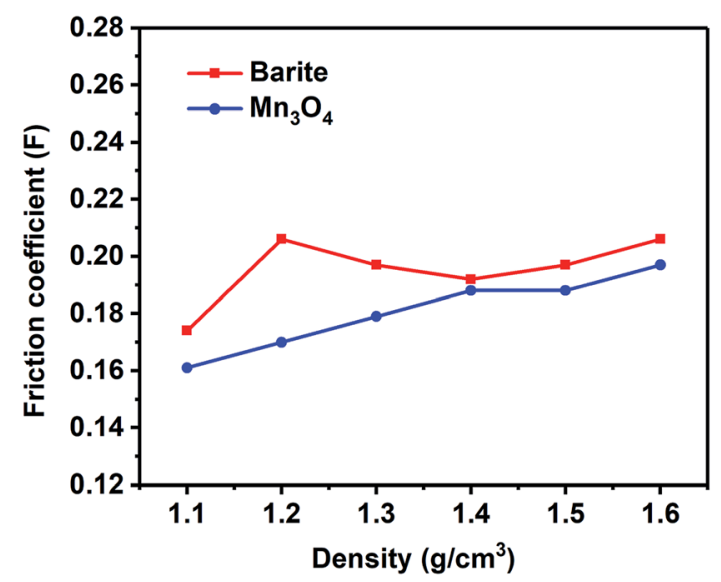

Fig. 18 Friction coefficient of barite/WDFs and $\mathrm{Mn}_{3} \mathrm{O}_{4} /$ WDFs with different densities.
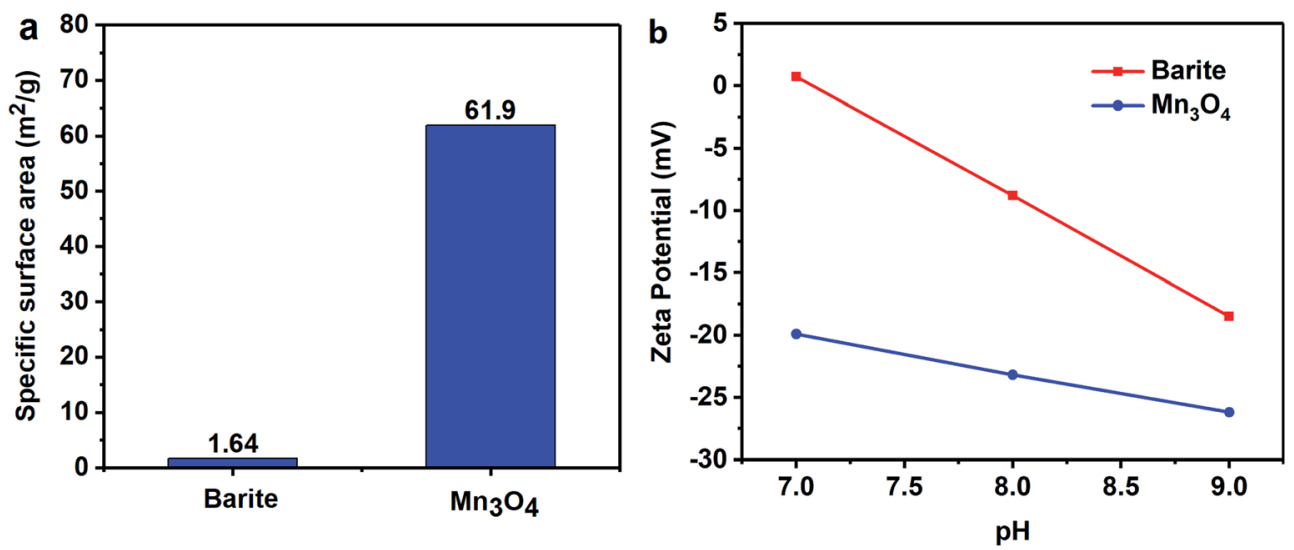

Fig. 17 (a) Specific surface area of barite and $\mathrm{Mn}_{3} \mathrm{O}_{4}$ and (b) zeta potential of barite and $\mathrm{Mn}_{3} \mathrm{O}_{4}$ in distilled water with different pH. 

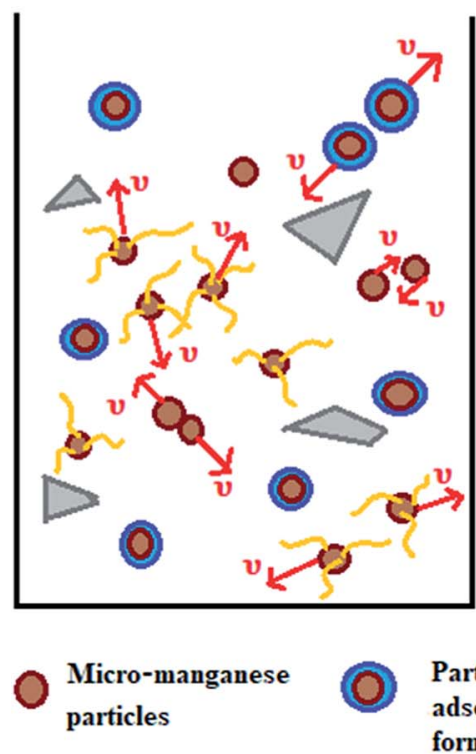

Particles that adsorbed water to form a hydrated membrane
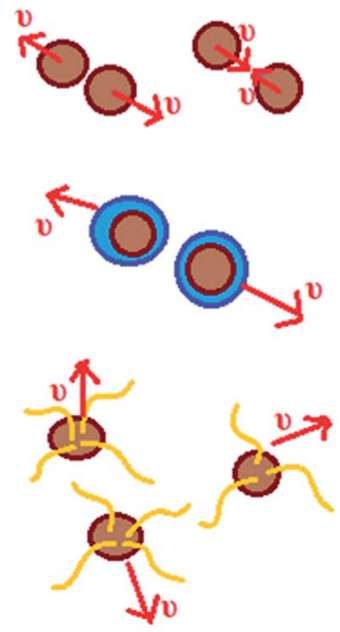

Particles that adsorbed polymer chains
Brownian motion caused the particles to collide and move irregularly.

The hydrated film was formed on the surface of the particles to prevent mutual contact between the particles.

Micro-manganese particles formed physical crosslinks with polymer chains, which made them repel each other.

Fig. 19 Schematic of the $\mathrm{Mn}_{3} \mathrm{O}_{4}$ suspension mechanism.

3.4.3 Suspension mechanism of $\mathrm{Mn}_{3} \mathrm{O}_{4}$. The suspension mechanism of $\mathrm{Mn}_{3} \mathrm{O}_{4}$ is shown in Fig. 19. The unique spherical structure of micro-manganese and its particle size much smaller than that of barite caused it to exhibit excellent suspension stability. Firstly, $\mathrm{Mn}_{3} \mathrm{O}_{4}$ particles with a particle size below $1 \mu \mathrm{m}$ resulted in strong Brownian motion in solution, which allowed the particles to make random collisions continually in the solution and weakened the effect of gravity on the particles. Secondly, the $\mathrm{Mn}_{3} \mathrm{O}_{4}$ particles had a much larger specific surface area than that of barite, resulting in highly adsorbability for water molecules and polymers in the drilling fluid. The hydrated film formed on the $\mathrm{Mn}_{3} \mathrm{O}_{4}$ particles and the physical crosslinks formed between $\mathrm{Mn}_{3} \mathrm{O}_{4}$ and polymer chains prevented adsorption between the particles, which reduced the sag caused by the aggregation of the small particles into large particles.

\section{Conclusion}

In this study, the effect of micro-manganese $\left(\mathrm{Mn}_{3} \mathrm{O}_{4}\right)$ and barite in drilling fluid was compared, and the sag stability of the weighting materials and the effect on the rheological properties of the drilling fluid were considered. Understanding the suspension mechanism is a prerequisite for improving the sag stability of weighting materials in drilling fluids. The suspension mechanism of $\mathrm{Mn}_{3} \mathrm{O}_{4}$ in the drilling fluid was also discussed.

The main conclusions of this study are as follows:

(1) The results of the static sag and dynamic sag experiments showed that $\mathrm{Mn}_{3} \mathrm{O}_{4}$ has much better suspension stability in drilling fluid than barite. The static sag and dynamic sag coefficients of $\mathrm{Mn}_{3} \mathrm{O}_{4} /$ WDFs can be kept within safe limits in the range of drilling fluid densities of 1.8 to $2.8 \mathrm{~g} \mathrm{~cm}^{-3}$, while that of the barite/WDFs were much higher that the safe range.
(2) $\mathrm{Mn}_{3} \mathrm{O}_{4}$ could also improve the rheology of the drilling fluids. The $\mathrm{Mn}_{3} \mathrm{O}_{4} / \mathrm{WDFs}$ could maintain reasonable viscosity and a much higher gel strength even at a density of $2.8 \mathrm{~g} \mathrm{~cm}^{-3}$.

(3) In the barite/WDF, the viscosity increased rapidly with an increase in drilling fluid density, which is the main reason for the improvement in its filtration performance. However, a thick filter cake was formed due to the severe sag of barite. In the $\mathrm{Mn}_{3} \mathrm{O}_{4}$ / WDFs, the positive impact of reduced permeability on filtration rate was not sufficient to offset the adverse effects of other factors, and thus the filtrate volume was higher than that of the barite/WDFs.

(4) A uniform spherical structure of less than $1 \mu \mathrm{m}$ reduced the friction of the $\mathrm{Mn}_{3} \mathrm{O}_{4}$ particles in the drilling fluid, which not only slowed down the increase in the $\mathrm{AV}$ of the $\mathrm{Mn}_{3} \mathrm{O}_{4}$ / WDFs with an increase in density, but also reduced the friction coefficient of the $\mathrm{Mn}_{3} \mathrm{O}_{4} / \mathrm{WDF}$.

(5) The specific surface area of the $\mathrm{Mn}_{3} \mathrm{O}_{4}$ particles was much higher than that of barite, resulting in the strong adsorption of the $\mathrm{Mn}_{3} \mathrm{O}_{4}$ particles on water molecules and polymers in the drilling fluid. The formation of a hydration film and physical crosslinking with polymer chains prevented sagging caused by the adsorption of small particles to form large particles.

The study of the suspension mechanism illustrates the reason why $\mathrm{Mn}_{3} \mathrm{O}_{4}$ improved the suspension capacity of the drilling fluids, and provides a basis for better the application of $\mathrm{Mn}_{3} \mathrm{O}_{4}$ in drilling fluids and further improving the sag stability of barite in drilling fluids.

\section{Conflicts of interest}

There are no conflicts to declare.

\section{Acknowledgements}

We would like to thank for the financial support from Natural Nature Science Foundation of China (J218076), national Key 
R\&D Program of china (2016YFE0202200 and PY201802) for this work.

\section{References}

1 T. H. Omland, A. Saasen, C. Van Der Zwaag and P. A. Amundsen, presented in part at the Asia Pacific Oil and Gas Conference and Exhibition, Jakarta, Indonesia, 30 October-1 November, 2007.

$2 \mathrm{M}$. Amighi and K. Shahbazi, presented in part at the SPE Deep Gas Conference and Exhibition, Manama, Bahrain, 24-26 January, 2010.

3 S. Elkatatny, Energies, 2018, 11.

4 K. Bybee, J. Pet. Technol., 2004, 56, 62-63.

5 K. A. Fattah and A. Lashin, J. Afr. Earth Sci., 2016, 117, 345357.

6 P. A. Bern, M. Zamora, K. S. Slater and P. J. Hearn, presented in part at the SPE Annual Technical Conference and Exhibition, Denver, Colorado, 6-9 October, 1996.

7 M. R. Amighi and K. Shahbazi, Pet. Sci. Technol., 2011, 29, 1864-1872.

8 P. A. Bern, E. van Oort, B. Neustadt, H. Ebeltoft, C. Zurdo, M. Zamora and K. S. Slater, SPE Drill. Completion, 2000, 15, 25-30.

9 T. Nguyen, S. Miska, M. Yu, N. Takach, R. Ahmed, A. Saasen, T. H. Omland and J. Maxey, J. Pet. Sci. Eng., 2011, 78, 160165.

10 W. Dye, T. Hemphill, W. Gusler and G. Mullen, SPE Drill. Completion, 2001, 16, 27-34.

11 A. Naderi and K. Shahbazi, Pet. Sci. Technol., 2014, 32, 84-90.

12 P. Xu, M. Xu, Z. Tao, Z. Wang and T. Huang, R. Soc. Open Sci., 2018, 5, 180358.

13 W. Muller and M. Karad, Oil Gas Eur. Mag., 2009, 35, 117120.

14 M. R. Gregoire, M. H. Hodder, S. Peng and J. Massam, presented in part at the SPE/IADC Drilling Conference and Exhibition, Amsterdam, The Netherlands, 17-19 March, 2009.

15 G. Quercia, R. Belisario and R. Rengifo, Wear, 2009, 266, 1229-1236.

16 B. Mohamed and A. Ebrahim, in Advances in Biology, Bioengineering and Environment, ed. N. Mastorakis, V. Mladenov, M. Demiralp and A. Bojkovic, World Scientific and Engineering Acad and Soc, Athens, 2010, pp. 114-118.

17 A. Gadalla, R. Pino, P. Ezi, N. Zayer, M. Al Hudaithi, A. Addagalla, B. Kosandar, P. Jadhav, I. Lawal, A. Imran and O. Hassan, presented in part at the SPE Middle East Oil $\&$ Gas Show and Conference, Manama, Kingdom of Bahrain, 6-9 March, 2017.

18 N. E. Blomberg and B. Melberg, J. Pet. Technol., 1984, 36, 969-974.

19 K. Bybee, J. Pet. Technol., 2008, 60, 81-82.

20 S. M. Zhou, G. S. Li and Q. C. Wang, Pet. Explor. Dev., 2013, 40, 115-118.

21 A. S. Al-Yami and H. A. Nasr-El-Din, presented in part at the SPE Annual Technical Conference and Exhibition, Anaheim, California, U.S.A., 11-14 November, 2007.
22 C. Steele, W. L. Hart and D. Oakley, presented in part at the Offshore Mediterranean Conference and Exhibition, Ravenna, Italy, 11-14 March, 2007.

23 A. S. Al-Yami, H. A. Nasr-El-Din, M. A. Al-Shafei and M. A. Bataweel, presented in part at the SPE Eastern Regional/AAPG Eastern Section Joint Meeting, Pittsburgh, Pennsylvania, USA, 11-15 October, 2008a.

24 A. S. Al-Yami, H. A. Nasr-El-Din, M. A. Bataweel, A. A. AlMajed and H. Menouar, presented in part at the SPE International Symposium and Exhibition on Formation Damage Control, Lafayette, Louisiana, USA, 13-15 February, $2008 \mathrm{~b}$.

25 V. Wagle, A. S. Al-Yami, Z. AlAbdullatif, A. S. Bubshait and A. AlSafran, presented in part at the SPE North Africa Technical Conference and Exhibition, Cairo, Egypt, 14-16 September, 2015.

26 K. van Netten, J. Zhou, K. P. Galvin and R. Moreno-Atanasio, Chem. Eng. Sci., 2013, 93, 229-237.

27 N. M. Kovalchuk and V. M. Starov, Adv. Colloid Interface Sci., 2012, 179-182, 99-106.

28 A. M. Al Moajil, A. I. Rabie, H. A. Nasr-El-Din, M. Al-Bagoury and C. D. Steele, presented in part at the Offshore Technology Conference Asia, Kuala Lumpur, Malaysia, 22-25 March, 2016.

29 Z. A. Alabdullatif, A. S. Al-Yami, V. B. Wagle, A. S. Bubshait and A. M. Al-Safran, presented in part at the Abu Dhabi International Petroleum Exhibition and Conference, $\mathrm{Abu}$ Dhabi, UAE, 10-13 November, 2014.

30 Y. Kar, A. M. Al-Moajil, H. A. Nasr-El-Din, M. Al-bagoury and C. D. Steele, presented in part at the SPE Middle East Oil and Gas Show and Conference, Manama, Bahrain, 25-28 September, 2011.

31 A. Rehman, A. M. Al Moajil, H. A. Nasr-El-Din, M. Al-bagoury and C. D. Steele, presented in part at the SPE Latin America and Caribbean Petroleum Engineering Conference, Mexico City, Mexico, 16-18 April, 2012.

32 A. M. Al Moajil, H. A. Nasr-El-Din, Y. Kar, M. Al-Bagoury and C. D. Steele, presented in part at the Abu Dhabi International Petroleum Exhibition and Conference, Abu Dhabi, UAE, 9-12 November, 2015.

33 G. Chern, L. Horng, M. Z. Lin, S. M. Li, D. S. Lee, T. Y. Hou, M. F. Tai and T. H. Wu, J. Magn. Magn. Mater., 2000, 209, 138-141.

34 A. M. Al Moajil and H. A. Nasr-El-Din, J. Can. Pet. Technol., 2013, 52, 64-74.

35 A. M. Al Moajil, H. A. Nasr-El-Din, A. S. Al-Yami, A. D. AlAamri and A. K. Al-Agil, presented in part at the SPE International Symposium and Exhibition on Formation Damage Control, Lafayette, Louisiana, USA, 13-15 February, 2008.

36 A. M. Al Moajil and H. A. Nasr-El-Din, J. Can. Pet. Technol., 2014, 53, 122-130.

$37 \mathrm{~J}$. Maxey, presented in part at the Nordic Rheology Conference, Stavanger, Norway, June, 2007.

38 A. E. Bayat, P. J. Moghanloo, A. Piroozian and R. Rafati, Colloids Surf., A, 2018, 555, 256-263. 
39 V. Wagle, A. S. Al-Yami, M. Aljubran and H. Al-Bahrani, presented in part at the SPE Kingdom of Saudi Arabia Annual Technical Symposium and Exhibition, Dammam, Saudi Arabia, 8/16/2018.

40 M.-C. Li, Q. Wu, K. Song, C. F. De Hoop, S. Lee, Y. Qing and Y. Wu, Ind. Eng. Chem. Res., 2016, 55, 133-143.

41 K. Elshreef, J. Pet. Environ. Biotechnol., 2013, 4, 1000157.
42 L. Yan, C. Wang, B. Xu, J. Sun, W. Yue and Z. Yang, Mater. Lett., 2013, 105, 232-235.

43 D. Buelichen and J. Plank, J. Appl. Polym. Sci., 2012, 124, 2340-2347.

44 D. Wen, G. Lin, S. Vafaei and K. Zhang, Particuology, 2009, 7, 141-150. 